\title{
Migraine Treatment: Current Acute Medications and Their Potential Mechanisms of Action
}

\author{
Jonathan Jia Yuan Ong ${ }^{1,2,3} \cdot$ Milena De Felice ${ }^{4}$
}

Published online: 12 December 2017

(C) The American Society for Experimental NeuroTherapeutics, Inc. 2017

\begin{abstract}
Migraine is a common and disabling primary headache disorder with a significant socioeconomic burden. The management of migraine is multifaceted and is generally dichotomized into acute and preventive strategies, with several treatment modalities. The aims of acute pharmacological treatment are to rapidly restore function with minimal recurrence, with the avoidance of side effects. The choice of pharmacological treatment is individualized, and is based on the consideration of the characteristics of the migraine attack, the patient's concomitant medical problems, and treatment preferences. Notwithstanding, a good understanding of the pharmacodynamic and pharmacokinetic properties of the various drug options is essential to guide therapy. The current approach and concepts relevant to the acute pharmacological treatment of migraine will be explored in this review.
\end{abstract}

Keywords Migraine acute treatment $\cdot$ Pharmacology $\cdot$ Therapeutics

\section{Introduction}

Migraine is a common primary headache disorder and is the seventh leading cause of disability, and was the leading cause of neurological disability globally in 2015 [1]. In the USA, migraine affects approximately $18 \%$ of women, $6 \%$ of men, and causes a $50 \%$ reduction in work or school productivity in nearly $50 \%$ of affected individuals during attacks, with absenteeism at work or school of at least 1 day every 3 months [2]. The main aim of acute migraine pharmacotherapy is to control symptoms in order to minimize the functional disability on an individual

This article was updated to correct an error in figure 1 introduced during the production process.

Jonathan Jia Yuan Ong

jonathan_ong@nuhs.edu.sg

1 Headache Group, Department of Basic and Clinical Neuroscience, Institute of Psychiatry, Psychology and Neuroscience, Kings College London, London, UK

2 NIHR-Wellcome Trust King's Clinical Research Facility, Kings College Hospital, London, UK

3 Department of Medicine, Division of Neurology, National University Health System, University Medicine Cluster, Singapore, Singapore

4 School of Clinical Dentistry, The University of Sheffield, Sheffield, UK patient's life. The pharmacologic approach is dichotomously categorized into acute (to relieve a migraine attack) and preventive (to reduce frequency, duration, and intensity of attacks) treatment. It is important that patients understand the rationale and differences between these 2 approaches and the medications used are vastly different. It is estimated that $>90 \%$ of migraineurs would have used some form of acute medication [3]. The management of migraine is multifaceted and often also involves modalities other than medications [4]. This review will focus on the clinical approaches and the relevant pharmacology of acute migraine treatment.

\section{Migraine Symptomatology}

Migraine is characterized by attacks of unilateral throbbing headache, associated with photophobia, phonophobia, osmophobia, nausea, vomiting, cranial allodynia, or movement sensitivity, which may last for 4 to $72 \mathrm{~h}$ [5]. Up to $48 \mathrm{~h}$ prior (the premonitory phase), and during the headache phase, patients often experience a constellation of cognitive (reduced concentration), affective (mood changes), and cranial autonomic symptoms (e.g., conjunctival injection, lacrimation, nasal congestion, or rhinorrhea). Other symptoms include appetite, thirst, and micturition changes $[6,7]$. In the postdrome phase (the period after the headache), most experience a sense of generalized lethargy or fatigue, which may last for several 
hours up to a day [8]. Migraine aura (transient focal neurological deficit(s) characterized by visual, sensory, language/ speech, or motor abnormalities) may be experienced in approximately one-third of migraineurs and it may occur before or during the headache phase [9].

\section{Pathophysiology}

The advancement in the understanding of migraine pathophysiology over the last 2 decades, has not only allowed the development of novel target-based therapeutic approaches, but it is also contributing to clarification of the rationale for several current pharmacotherapeutic approaches that have been used in the acute treatment of migraine. There is substantial evidence that diencephalic and brainstem nuclei are involved in the modulation of trigeminovascular activation $[10,11]$, which consists of efferent projections innervating durovascular structures, and afferent projections from these structures back to the trigeminal nucleus caudalis (see Fig. 1). The activation of these pathways culminates in meningeal vasodilation, neurogenic inflammation, central sensitization, and is eventually perceived as head pain $[12,13]$. In addition, many neuropeptides are purported to be involved in the migraine circuitry both peripherally and centrally (see Fig. 1) [14]. The now widely accepted neurovascular hypothesis posits that migraine is a disorder of the endogenous pain modulating system, and can be viewed as an inherited dysfunction of sensory modulatory network with homeostatic perturbations causing abnormal processing of essentially normal neural traffic [10].

\section{Objectives and Approaches of Acute Migraine Treatment}

The main objective of the acute treatment of migraine is to decrease functional disability through the reduction of attack duration and severity. The US Headache Consortium has outlined the objectives for acute migraine treatment, which serve as a useful guide for physicians [15]: 1) treat attacks rapidly and consistently without recurrence; 2) restore patient's ability to function; 3) minimize the use of back-up and rescue medications; 4) optimize self-care and reduce subsequent use of resources; 5 ) to be cost-effective for overall management; 6) have minimal or no adverse events.

In addition, the International Headache Society Clinical Trial Guidelines suggest that the percentage of study participants headache-free at $2 \mathrm{~h}$ should be routinely used as the primary outcome in acute therapy trials [16]. Sustained pain freedom with the absence of other migraine symptoms at 24 or $48 \mathrm{~h}$ are also relevant outcome measures [16]. Although these parameters are used mainly in the research context, they are perhaps equally applicable clinically, and are worth considering when evaluating the effectiveness of acute treatment.

In an updated literature review, the American Headache Society addressed the efficacy of medications used for acute migraine treatment [17]. These studies used one or a combination of multiple endpoints of efficacy, including headache relief (i.e., reduction from severe or moderate intensity to mild or none), headache freedom, decreased disability, absence of nausea or vomiting, and absence of photophobia or phonophobia (increased sensitivity to light or sounds). Outcomes were measured at varying intervals following the administration of different medications. This and other evidence-based guidelines provide a useful guide for assessing which medications have demonstrated superiority when compared with placebo, and the strength of the evidence supporting that superiority [17]. The pharmacological treatment options can be divided into migraine specific and migraine nonspecific drugs. Several of these medication categories will be discussed.

\section{Medication Choices}

The choice of acute medication for the treatment of migraine attacks should match the patient's needs, and is largely dependent on the attack characteristics such as the severity of the headache, frequency, disability, associated symptoms, and time-to-peak. These factors should be considered in the context of an individual patient's other concomitant medical problems.

The treatment of acute migraine attacks can seem daunting to both the physician and patient, given the multitude of pharmacological options that are available, and that migraine attacks are generally treated in settings where the patient must usually administer treatment without the assistance of a healthcare provider. The physician should consider the following when choosing an appropriate treatment for a patient: 1) headache intensity and disability 2) nausea; 3 ) tempo of headache pain escalation; 4) early intervention; 5) headache recurrence; 6) combination treatments; 7) avoid overuse of medications; 8) avoid use of opioids and barbiturates.

\section{Headache Intensity and Disability}

When deciding the appropriate course of treatment, it is useful to consider the severity of the migraine attack. If headaches are mild to moderate in intensity, acetaminophen or a nonsteroidal anti-inflammatory drug (NSAID) may be started first. This strategy has been found to be the most appropriate unless the patient has already tried over-the-counter medications. If this proves unsuccessful the triptan strategy can be tried next. However, for patients who have severe disabling attacks, the 


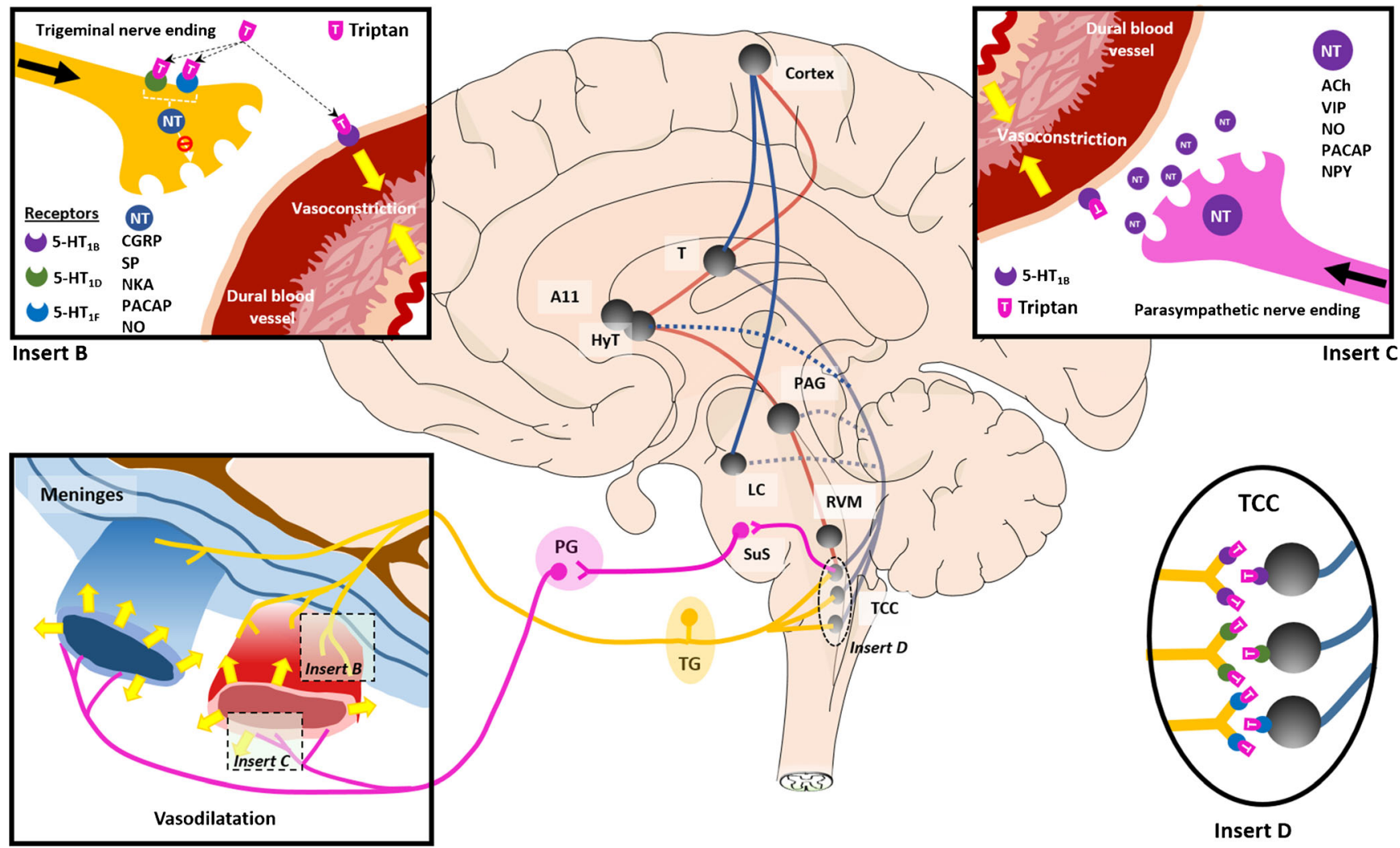

\section{Insert A}

Fig. 1 Trigeminovascular sensory afferents (yellow lines) from the meningeal vessels pass through the trigeminal ganglion (TG) and synapse on the second-order neurons in the trigeminocervical complex (TCC). These neurons, in turn, ascend through the quintothalamic tract, and after decussating in the brainstem, they form synapses with neurons in the thalamus (T), and, in turn, send ascending signals to the cortex (blue lines). There is a reflex connection with the parasympathetic outflow (pink lines) to the cranial vasculature via the superior salivatory nucleus $(\mathrm{SuS})$ mediated through the pterygopalatine ganglion (PG). These pathways are activated with the release of various neurotransmitters (NT) resulting in vasodilatation (insert A). At the trigeminal nerve ending, the purported neurotransmitters involved are calcitonin gene related peptide (CGRP), substance P (SP), neurokinin A (NKA), and pituitary adenylate cyclase-activating peptide (PACAP; insert B). At parasympathetic nerve endings, the purported neurotransmitters involved are acetylcholine (ACh), vasoactive intestinal peptide (VIP),

triptan strategy may immediately be preferred if there are no contraindications. Patients who have attacks of different severity may require more than one strategy at various times. When acute migraine attacks are refractory to treatment with NSAIDs or triptans, the occasional use of various rescue medications may be necessary [4].

Three basic approaches to choosing acute treatment have been identified based upon attack severity and migrainerelated disability: the stratified; the step-care-across-attacks; and the step-care-within-attacks [18].

In the "stratified" approach, the choice of medication is based on attack severity and disability. Essentially, the medication perceived to be most useful is administered first. Evidence suggests that this is the most effective approach nitrous oxide (NO), , and neuropeptide Y (NPY; insert C). Descending modulation of the trigeminovascular nociceptive inputs comes from the rostral ventromedial medulla (RVM), periaqueductal gray (PAG), hypothalamus (HyT), and A11 nucleus (red lines). There are further ascending connections (blue dotted lines) from the trigeminocervical complex (TCC) to the locus coeruleus (LC), PAG, and HyT, and indirectly to the cortex. These ascending and descending modulatory systems define the pain and the associated triggers and symptoms that may explain the clinical syndrome and duration of migraine [10]. The triptans are serotonin analogues and are agonists that act at 5-hydroxytryptamine $(5-\mathrm{HT})_{1 \mathrm{~B} / 1 \mathrm{D} / \mathrm{IF}}$ receptors. Centrally at the TCC, they are located on preand postsynaptic sites (insert D), decreasing the passage of nociceptive traffic [146]. Peripherally, they are located on prejunctional nerve endings innervating dural arterial blood vessels (insert B), preventing the release of mainly CGRP (via 5- $\mathrm{HT}_{1 \mathrm{D}}$ receptors), and on the vessels themselves causing vasoconstriction (via $5-\mathrm{HT}_{1 \mathrm{~B}}$ receptors) (insert $\mathrm{B}$ ) [146]

[18]. Patients with greater disability are initially started on a triptan, whereas patients with attacks of lesser intensity are likely to be given an NSAID first, which, if unsuccessful, would be followed by an escalation to a triptan in subsequent attacks. This approach is based on the assumption that triptans are more effective for severe migraine attacks than NSAIDs.

In the "step-care-across-attacks" approach, a less expensive medication or one with a better safety and tolerability profile is chosen first. If this is ineffective, other options are tried in turn for subsequent attacks. An NSAID or other nonspecific analgesic is administered first, and then escalated to a triptan for later attacks if the initial medication was not beneficial. This approach may result in several failed treatment attempts before arriving at an effective medication, with the 
consequence of frequent severe migraine attacks, leading to increased patient disability, and dissatisfaction with the physician-patient encounter. It may also result in over-reliance on over-the-counter medications.

With the "step-care-within-attack" approach, a patient takes a simple analgesic at the onset of the attack, and subsequently escalates to another medication class, in the course of the attack, if the initial medication fails to work. This approach may be effective for patients with attacks that increase in intensity slowly or for patients with attacks of variable severity.

These 3 approaches were investigated in the Disability in Strategies of Care (DISC) study [18], and it was found that "stratified" care is the most effective approach, suggesting that treatment should be matched and guided according to the level of disability. A subsequent post-hoc analysis demonstrated that this strategy was associated with lower healthcare costs than the other 2 approaches [19].

Although these strategies are discussed in isolation, in actual clinical practice, a combination of strategies may be seen. Most patients who eventually approach a physician for migraine would have already tried a number of analgesics prior to consultation, and thus the "step-care-across-attacks" approach would have already been started. For those with severe attacks, a "stratified" approach may have already been attempted. This has been termed the "combined acute medication treatment" approach [4].

\section{Nausea}

This is a common associated symptom of migraine and can be very disabling in a proportion of patients. The most appropriate route of medication administration should be selected based on the severity of nausea or if vomiting is present.

For patients without significant nausea, regular oral tablets are appropriate. Other formulations may also be applicable, including intranasal sprays, orally disintegrating tablets (wafers), and injections.

For patients with mild nausea, nausea exacerbated by fluid consumption, or when access to fluid is not possible, orally disintegrating triptan tablets (wafers) can be useful [20]. These are not absorbed through the buccal mucosa but are instead swallowed with saliva. Consequently, they do not necessarily have a faster onset of action than regular tablets.

For patients with moderate nausea, an antiemetic in combination with an NSAID or oral triptan can be administered. So far, oral metoclopramide $10 \mathrm{mg}$ has the best evidence [21-24]. Prochlorperazine $10 \mathrm{mg}$ is another option but shows higher risk of extrapyramidal side effects. Domperidone $10 \mathrm{mg}$ can also be used but has lower efficacy than metoclopramide [25, 26]. However, domperidone has the advantage of not causing extrapyramidal side effects, as it does not cross the blood-brain barrier. Despite concerns related to cardiac safety, the actual risk is low with intermittent usage in otherwise healthy individuals [27].

For patients with severe nausea, and those who may have vomiting events early in the course of a migraine attack, sumatriptan $6 \mathrm{mg}$ should be considered. In addition, triptan can also be used as nasal sprays formulation. Intranasal zolmitriptan $5 \mathrm{mg}$ (absorbed via the nasal mucosa) is a useful option, and has shown a significantly higher 2-h headache relief rate compared with the $2.5 \mathrm{mg}$ oral tablet formulation [28]. Intranasal sumatriptan and intranasal dihydroergotamine are also other options, but there is less evidence for significant amounts of transnasal absorption. In addition, suppository antiemetics such as prochlorperazine 10 to $25 \mathrm{mg}$ may be useful [29].

\section{Tempo of Headache Pain Escalation}

For migraine attacks that escalate in intensity very rapidly, and for those attacks that are fully developed upon awakening, a subcutaneous sumatriptan injection is the most effective treatment [30]. Other triptans that may be useful for rapidly increasing headache include rizatriptan, eletriptan, fast-dissolving sumatriptan tablet, nasal sumatriptan $20 \mathrm{mg}$, and nasal zolmitriptan $5 \mathrm{mg}$. Zolmitriptan nasal spray $5 \mathrm{mg}$ provides pain relief in some patients within $15 \mathrm{~min}$ (30\% absorbed through the nasal mucosa and enters the blood very rapidly), and pain-free responses exceed placebo at $30 \mathrm{~min}$ [31]. Several other medication formulations with a rapid onset of action may also be considered, including diclofenac powder for oral solution $50 \mathrm{mg}$ [32], solubilized ibuprofen $400 \mathrm{mg}$ [33], and effervescent acetylsalicylic acid (ASA) $1000 \mathrm{mg}$ [34].

For less severe attacks that build up more slowly but have a relatively long duration, slower but longer-acting options may be more beneficial when treatment is taken early in the attack, including naproxen (a NSAID) and frovatriptan.

\section{Early Intervention}

Acute medications, such as triptans, tend to be more effective if administered early in the course of the attack than when the attack has progressed or is fully established with features of central sensitization $[35,36]$. Lipton et al. [37] reported that the presence of allodynia significantly increased the likelihood of an inadequate response to triptans as measured by 2-h pain freedom and 24-h pain response. 


\section{Headache Recurrence}

Headache recurrence occurs when patients initially experience headache relief with treatment but subsequently experience the return of a moderate-to-severe headache within $24 \mathrm{~h}$. Patients should be advised to administer triptans early in the course of a headache while pain is still mild, as headache relief and pain-free response rates are higher and headache recurrence rates may also be lower [38]. If there was an initial response to a triptan, a second dose of the same triptan may be attempted, usually with a beneficial response [39]. If frequent recurrences after an initial triptan therapy occurs, one may consider switching to eletriptan or frovatriptan for future attacks as these triptans have relatively lower headache recurrence rates given their longer half-lives than other triptans $[40,41]$. The combination of a triptan and naproxen sodium 500 to $550 \mathrm{mg}$ provides greater efficacy than using either drug alone, with a higher 2-h headache relief rate [42], and higher 24-h sustained pain response [43]. In addition, intranasal or subcutaneous injection of dihydroergotamine may be useful [44].

\section{Combination Treatment}

Two or more acute medications can be combined if indicated. The most investigated combination is sumatriptan/ naproxen, which has been found to be more effective than when either drug is administered in isolation [42]. Metoclopramide can be added to a triptan or NSAID to treat nausea, and may also enhance absorption of these medications owing to its prokinetic effect. In addition, caffeine enhances the effectiveness of analgesics. However, one needs to consider the possible side effects of sleeprelated disturbances (if this is a migraine trigger) and caffeine-withdrawal headache when used frequently in high quantities.

\section{Avoid Overuse of Acute Medication}

Patients should be cautioned about the vicious cycle of frequent analgesic usage and its potential for headache worsening. The use of acetaminophen or NSAIDs on 15 or more days per month, or combination analgesics, opioids, ergotamines, or triptans on 10 or more days per month are considered to confer an increased risk for the development of medicationoveruse headache (MOH) [5]. The use of a headache diary should be encouraged not only to keep track of migraine headache days, but also to objectively record the frequency of acute treatment usage.
Avoid Use of Opioids and Barbiturates

Opiates, barbiturates, and combination analgesics containing either of these drugs should ideally not be chosen as first-line treatments. In the majority of patients, these medications are less effective than other options, and their frequent administration increases the propensity to develop $\mathrm{MOH}$.

\section{Specific Pharmacological Treatments for Acute Migraine}

\section{Ergot Alkaloids: Dihydroergotamine Mesylate}

Dihydroergotamine mesylate, an ergot derivative, was developed in 1943, and was intended to be a replacement for ergotamine tartrate as it has a better vascular side effect profile [45]. The molecular structure differs from ergotamine tartrate by the hydrogenation of the double bond at the 9 to 10 positions of the ergoline ring [46]. The main site of action for the compound is activation of the 5-hydroxytryptamine $(5-\mathrm{HT})_{1 \mathrm{~B}}$ and $5-\mathrm{HT}_{1 \mathrm{D}}$ serotonergic receptors thereby reduces trigeminal neuron activation $[47,48]$, and induces vasoconstriction of meningeal blood vessels (through action on $5-\mathrm{HT}_{1 \mathrm{~B}}$ receptors) $[49,50]$. Other receptors can also be activated, including 5$\mathrm{HT}_{1 \mathrm{~A}}, 5-\mathrm{HT}_{2 \mathrm{~A}}, 5-\mathrm{HT}_{1 \mathrm{~F}}, 5-\mathrm{HT}_{2 \mathrm{C}}, 5-\mathrm{HT}_{3}$, and dopamine $\mathrm{D} 1 /$ D2 receptor subtypes [51]. Dihydroergotamine mesylate also blocks the release of prostaglandins from glia, further stemming the activation of the trigeminal nucleus caudalis [52]. Other purported mechanisms of action involve blocking the adenosine triphosphate-mediated sensitization of trigeminal neurons; inhibiting the release of stimulated calcitonin generelated peptide; and decreasing purinergic receptor P2X ligand-gated ion channel 3 membrane expression via activation of the $\alpha 2$-adrenoreceptors [53].

Although dihydroergotamine mesylate has fewer adverse effects than ergotamine tartrate, it can cause significant nausea and vomiting when administered intravenously (IV), intramuscularly, or subcutaneously. It has also been reported that administration of dihydroergotamine mesylate may results in bilateral lower limb cramps, chest discomfort, transient worsening of headache, diarrhea, and abdominal cramps [54].

In 1945, Horton et al. [55], reported their experience involving the treatment of migraineurs with dihydroergotamine administered via the intravascular and intramuscular routes. Pain relief was attained in $75 \%$ and $89 \%$ of subjects, respectively. A lower occurrence of nausea with dihydroergotamine mesylate than with ergotamine tartrate was reported. Subsequently, the usefulness and tolerability of repeated IV dihydroergotamine mesylate administration was studied, and it is now an established treatment for refractory migraine [56, 57]. In a retrospective study involving 110 chronic migraineurs admitted for treatment, and receiving an average 
dose of IV dihydroergotamine mesylate of $11.25 \mathrm{mg}$ over 5 days [54], 66 patients $(67 \%)$ reported headache freedom during treatment, and 85 patients $(75 \%)$ reported headache freedom within 1 month post-treatment. Good symptomatic control of nausea was found to have a positive predictive effect on the outcome of such treatment.

The American Academy of Neurology guidelines suggest a maximum daily dose of dihydroergotamine mesylate of $3 \mathrm{mg}$ (up to $20 \mathrm{mg}$ per week) [58]. Titration to a subnauseating dose is preferable, and the presence of nausea (through activation of 5- $\mathrm{HT}_{2}$ and $5-\mathrm{HT}_{3}$ receptors) suggests that too high a dose has been administered. Other routes of administration include self-injection, either subcutaneously or intramuscularly [59]. An intranasal formulation is available (Migranal), it is relatively well tolerated, apart from prolonged nasal congestion, and is associated with and inconsistent systemic dosage delivery. MAP0004 (Levadex) is a dihydroergotamine mesylate formulation delivered by oral inhalation using the TEMPO inhaler (MAP Pharmaceuticals, Irvine, CA, USA), and is presently in the process of seeking approval from the US Food and Drugs Administration [60].

\section{Ergot Alkaloids: Ergotamine}

Ergotamine was first isolated by Stoll [61] and has been used in the acute treatment of migraine since 1926 [62]. Similar to dihydroergotamine mesylate, ergotamine interacts with a variety of receptors, including the 5-HT, dopamine, and noradrenaline receptors [63]. Owing to high first-pass metabolism, ergotamine has a very low bioavailability $(<1 \%)$ when administered orally compared with the IV route (100\% bioavailability) [64]. Administered per rectally (suppository), the bioavailability is $1 \%$ to $3 \%$ [65]. Ergotamine is metabolized by the liver and metabolites are excreted in the bile, with an elimination half-life of $2 \mathrm{~h}$ [65].

Most physicians feel that there is some place for ergotamine in the acute treatment of migraine. However, there is no consensus as to its place in clinical practice. Tfelt-Hansen et al. [63] reviewed 18 randomized controlled clinical trials involving oral ergotamine, or oral ergotamine plus caffeine (e.g., cafergot), at an initial ergotamine dose ranging from 1 to $5 \mathrm{mg}$ [63]. After assessing the quality of the evidence, they concluded that there was nonuniformity pertaining to the utility of oral ergotamine in the treatment of migraine based on the conflicting outcomes of these trials [63]. Despite their findings, consensus recommendations on the role of ergotamine in the acute treatment of migraine have been suggested. Patients who having been prescribed ergotamine (during the pretriptan era) and who are responding satisfactorily with no contraindications to its use and with no signs of dose escalation could potentially continue on this medication. In special cases, where patients have attacks lasting $>48 \mathrm{~h}$, ergotamine may be useful. Furthermore, patients with frequent headache recurrence could benefit with ergotamine as headache recurrence is probably less likely [66]. The recommended single dose per attack ranges from 0.5 to $2 \mathrm{mg}$, depending on efficacy and tolerability for nausea, and should be administered as early as possible in the course of the attack [65]. The per rectal route generally results in improved absorption versus the oral route of administration [63].

As a result of ergotamine's low degree of receptor selectivity, drug-induced side effects are increased. Animal studies have shown that the vasoconstrictor effect of ergotamine is particularly significant within the carotid vasculature, whereas blood flow to other tissues including the brain is affected to a small extent $[67,68]$. In humans, ergotamine causes vasoconstriction in the pulmonary, cerebral, and coronary arteries [69-71]. Ergotamine produces coronary vasoconstriction, with ischemic changes and angina in patients with underlying coronary artery disease [72]. Other side effects include nausea and/or vomiting, (probably as a direct effect on central nervous system emetic centers) leg weakness, numbness, and tingling of the extremities. Ergotamine is contraindicated in women who are or may become pregnant, as the drug may harm the developing fetus, in those with peripheral vascular disease, coronary heart disease, uncontrolled hypertension, stroke, and impaired renal or hepatic function. In addition, ergotamine should be avoided in patients with hemiplegic migraine, migraine with brainstem aura, and migraine with prolonged aura [63].

\section{Triptans}

As a class of drugs, the triptans, were specifically developed for the acute treatment of migraine. Triptans are 5-HT receptor agonists (selective for $5-\mathrm{HT}_{1}$ receptors), and are analogues of the neurotransmitter serotonin (5-HT). Peripherally, the activity of triptans at the $5-\mathrm{HT}_{1 \mathrm{~B}}$ receptors reduces pain induced by cranial vasodilation through vasoconstriction [73], whereas their activity at the $5-\mathrm{HT}_{1 \mathrm{D}}$ receptors blocks the release of vasoactive peptides that trigger neurogenic inflammation. Centrally, the triptans interfere with the afferent return of nociceptive signals to the trigeminal nucleus caudalis (see Fig. 1) $[74,75]$.

Sumatriptan was the pioneer of this class of drugs to be synthesized. It was synthesized in the UK by Patrick Humphrey and colleagues with the aim of formulating a drug that had ergot-like properties but without the adverse effects of vasoconstriction [76-80]. In the 1960s, it was postulated that vasoconstriction produced by 5-HT, ergotamine, and noradrenaline reduced migraine attacks, and, by 1991, sumatriptan was introduced globally. Injectable subcutaneous sumatriptan was the first member in the triptan class to be available worldwide. At present, there are 7 different triptans marketed. Sumatriptan, zolmitriptan, rizatriptan, naratriptan, almotriptan, and frovatriptan bind to both $5-\mathrm{HT}_{1 \mathrm{~B}}$ and $5-\mathrm{HT}_{1 \mathrm{D}}$ receptors. 
Eletriptan binds to $5-\mathrm{HT}_{1 \mathrm{~B}}, 5-\mathrm{HT}_{1 \mathrm{D}}$ and $5-\mathrm{HT}_{1 \mathrm{~F}}$ receptors. They are members of the tryptamine family, and derivatives of the intercellular signal molecule indole, with substitutions in positions 3 and 5 (see Table 1). The structure of indole is similar to the structure of 5-HT and the side chains on the indole ring are different for the various triptans. The main difference is the presence of the sulfonamide moiety with a different side chain attached to it in position 5 and the presence of a nitrogen-alkyl chain in position 3. Rizatriptan, zolmitriptan, and frovatriptan have a 2-oxazolidone and an amide instead of a sulfonamide and a triazole, respectively. In the chemical structure of eletriptan, the nitrogen-alkyl chain connected to the indole ring is replaced with a dimethylpyrrolidine, whereas in naratriptan the nitrogen-alkyl chain is replaced with a 1methylpiperidine ring.

Triptans can be categorized into 2 main groups. Sumatriptan, zolmitriptan, rizatriptan, almotriptan, and eletriptan, belonging to group 1 , have a faster onset of action. Naratriptan and frovatriptan, belonging to group 2, have a slower onset of action (see Table 1). In addition, head-tohead trials have suggested that the triptans are as effective as NSAIDs [81].
Although individual triptans have similar molecular structures, pharmacokinetic differences exist which accounts for the differences in their efficacy, and tolerability profile (see Tables 4 and 5). In general, triptans are indicated for the treatment of moderate-to-severe migraine attacks [82]. Subcutaneous injection of sumatriptan $6 \mathrm{mg}$ has the lowest number needed to treat (NNT) for any triptan formulation. Among the oral triptans, eletriptan $40 \mathrm{mg}$ and rizatriptan $10 \mathrm{mg}$ conferred the highest pain-free rates at 2 h. Also, eletriptan has the highest 24-h sustained pain-free rate, defined as the absence of recurrence of headache for $24 \mathrm{~h} \mathrm{[40].} \mathrm{In} \mathrm{a} \mathrm{meta-analysis} \mathrm{of} 53$ clinical trials involving oral triptans for acute migraine treatment, Ferrari et al. [83] observed that all oral triptans were effective and well tolerated, with rizatriptan $10 \mathrm{mg}$, eletriptan $80 \mathrm{mg}$, and almotriptan $12.5 \mathrm{mg}$ providing the highest likelihood of consistent treatment success (see Table 2).

The response to a specific triptan cannot be predicted. Failure to one triptan does not predict failure to another [84]. However, if patients do not respond to their triptan for some attacks, with persistence of the head pain, as opposed to initial relief followed by recurrence, a second dose of a triptan is

Table 1 Currently available triptan formulations and their pharmacology

\begin{tabular}{|c|c|c|c|c|c|c|c|c|c|c|c|c|c|c|}
\hline Medication & $\begin{array}{l}\text { Chemical } \\
\text { structure }\end{array}$ & Formulations & $\begin{array}{c}\text { Usual \& } \\
\text { maximum dose } \\
\text { per day (mg) }\end{array}$ & $\begin{array}{l}\mathrm{T}_{\max } \\
(\mathrm{h})\end{array}$ & 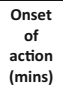 & $\begin{array}{l}T_{1 / 2} \\
\text { (h) }\end{array}$ & $\begin{array}{c}\text { Bio- } \\
\text { availability } \\
(\%)\end{array}$ & $\begin{array}{c}\text { NNT: } \\
2 \mathrm{~h} \\
\text { pain } \\
\text { free }\end{array}$ & Lipophilicity & $\begin{array}{c}\text { Protein } \\
\text { binding } \\
(\%)\end{array}$ & $v_{D}$ & Metabolism & $\begin{array}{l}\text { Route of } \\
\text { elimination }\end{array}$ & Comments \\
\hline & of thes & $\begin{array}{l}\text { ture of triptans consi } \\
\text { de with a different sic }\end{array}$ & $\begin{array}{l}n \text { indole ring tha } \\
n \text { attached to it a }\end{array}$ & $\begin{array}{l}\text { similar } \\
\text { sition }\end{array}$ & $\begin{array}{l}\text { he neu } \\
\text { 1) and }\end{array}$ & $\begin{array}{l}\text { ransmi } \\
\text { preser }\end{array}$ & $\begin{array}{l}\text { 5HT. The } \\
\text { of nitroge }\end{array}$ & $\begin{array}{l}\text { chain } \\
\text { yl cha }\end{array}$ & $\begin{array}{l}\text { this ring a } \\
\text { t position }\end{array}$ & ferent & & riptans. & n differe & sence \\
\hline \multicolumn{15}{|c|}{ Group 1 - Fast-acting triptans } \\
\hline $\begin{array}{l}\text { Sumatriptan } \\
\text { Imitrex } \\
\text { Imgran }^{(19}\end{array}$ & & $\begin{array}{l}\text { Tablets 25, 50, } 100 \mathrm{mg} \\
\text { Nasal spray 5, } 20 \mathrm{mg} \\
\text { SC injection 4, } 6 \mathrm{mg} \\
\text { Suppositories (EU) } 25 \mathrm{mg}\end{array}$ & $\begin{array}{l}50,100 \text { (usual), } \\
200 \text { (maximum) } \\
20 \text { (usual), } 40 \\
\text { (maximum) } \\
4-6 \text { (usual)), } 12 \\
\text { (maximum) } \\
50 \text { (maximum) } \\
\end{array}$ & $\begin{array}{l}2 \\
1-1.5 \\
0.2\end{array}$ & $\begin{array}{l}30-60 \\
15-30 \\
10-15 \\
30-60\end{array}$ & 2 & $\begin{array}{l}14 \\
17 \\
97\end{array}$ & $\begin{array}{l}4.7- \\
6.1 \\
4.7 \\
\\
2.3\end{array}$ & Low & $\begin{array}{ll}10-21 \\
\end{array}$ & $\begin{array}{l}2.4- \\
3.3 \\
\mathrm{~L} / \mathrm{kg}\end{array}$ & $\begin{array}{l}\text { Hepatic } \\
\text { MAO-A }\end{array}$ & $\begin{array}{l}\text { Urine } \\
(57 \%) \\
\text { Faecal } \\
(38 \%)\end{array}$ & 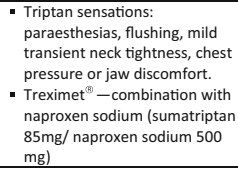 \\
\hline $\begin{array}{l}\text { Zolmitriptan } \\
\text { Zomig }^{\otimes}\end{array}$ & & $\begin{array}{l}\text { Tablets } 2.5,5.0 \mathrm{mg} \\
\text { Orally disintegrating } \\
\text { tablets } 2.5,5.0 \mathrm{mg} \\
\text { Nasal spray } 5.0 \mathrm{mg}\end{array}$ & $\begin{array}{l}2.5-5 \text { (usual), } 10 \\
\text { (maximum) } \\
2.5 \mathrm{mg} \text { (usual), } 10 \\
\text { (maximum) } \\
5 \text { (usual), } 10 \\
\text { (maximum) }\end{array}$ & $\begin{array}{l}2 \\
3.3\end{array}$ & 45 & $2.5-3.0$ & 40 & 5.9 & Moderate & 25 & $\begin{array}{l}7.0 \\
\mathrm{~L} / \mathrm{kg}\end{array}$ & $\begin{array}{l}\text { Hepatic } \\
\text { CYP1A2 } \\
\text { MAO-A }\end{array}$ & $\begin{array}{l}\text { Urine } \\
(8 \%) \\
\text { Faecal } \\
(30 \%)\end{array}$ & $\begin{array}{l}\text { - Triptan sensations. } \\
\text { - Contraindicated specifically in } \\
\text { patients with Wolf-Parkinson- } \\
\text { White syndrome. }\end{array}$ \\
\hline $\begin{array}{l}\text { Rizatriptan } \\
\text { Maxalt }^{\otimes} \\
\text { Rizalt }^{\mathbb{E}}\end{array}$ & & $\begin{array}{l}\text { Tablets } 5.0,10 \mathrm{mg} \\
\text { Orally disintegrating } \\
\text { tablets } 5.0,10 \mathrm{mg}\end{array}$ & $\begin{array}{l}10 \mathrm{mg} \text { (usual) } \\
20 \text { (maximum) }\end{array}$ & $\begin{array}{l}1.2 \\
1.6-2.5\end{array}$ & $30-120$ & $2.0-3.0$ & 45 & 3.1 & Moderate & 14 & $\begin{array}{l}110- \\
140 \\
\mathrm{~L}\end{array}$ & $\begin{array}{l}\text { Hepatic } \\
\text { MAO-A }\end{array}$ & $\begin{array}{l}\text { Urine } \\
(8-16 \%)\end{array}$ & $\begin{array}{l}\text { - Triptan sensations. } \\
\text { - Propranolol raises rizatriptan } \\
\text { serum levels. Reduce the dose } \\
\text { to } 5 \mathrm{mg} \text { when used } \\
\text { concomintantly. }\end{array}$ \\
\hline $\begin{array}{l}\text { Almotriptan } \\
\text { Axert }^{\text {क }}\end{array}$ & & Tablets $6.25,12.5 \mathrm{mg}$ & $\begin{array}{l}12.5 \text { (usual) } \\
25 \text { (maximum) }\end{array}$ & $1.4-3.8$ & $60-180$ & $3.2-3.7$ & 80 & 4.3 & - & 35 & $\begin{array}{l}180- \\
200 \\
L\end{array}$ & $\begin{array}{l}\text { Hepatic, } \\
\text { MAO-A } \\
\text { CYP2D6 } \\
\text { CYP3A4 } \\
\end{array}$ & $\begin{array}{l}\text { Urine } \\
(40 \%) \\
\text { Faecal } \\
(13 \%) \\
\end{array}$ & $\begin{array}{l}\text { - Well tolerated, occasional } \\
\text { triptan sensations. }\end{array}$ \\
\hline $\begin{array}{l}\text { Eleptriptan } \\
\text { Relpax }\end{array}$ & & Tablets 20, $40 \mathrm{mg}$ & $\begin{array}{l}40 \text { (usual) } \\
80 \text { (maximum) }\end{array}$ & $1.0-2.0$ & $<60$ & $3.6-5.5$ & 50 & 4.5 & High & 85 & $\begin{array}{l}138 \\
L\end{array}$ & $\begin{array}{l}\text { Hepatic } \\
\text { CYP 3A4 }\end{array}$ & $\begin{array}{l}\text { Non-renal } \\
\text { clearance } \\
(90 \%)\end{array}$ & $\begin{array}{l}\text { - Metabolism exclusively } \\
\text { through the CYP3A4 system. } \\
\text { Precautions needed when } \\
\text { concomitantly administered } \\
\text { with CYP3A4 inhibitors } \\
\text { (antifungals, macrolide } \\
\text { antibacterials, anti-HIV drugs, } \\
\text { verapamil, grapefruit juice). }\end{array}$ \\
\hline \multicolumn{15}{|c|}{ Group 2 - Slow-acting triptans } \\
\hline $\begin{array}{l}\text { Naratriptan } \\
\text { Amerge }^{\circledR} \\
\text { Naramig }^{\circledR} \\
\end{array}$ & & Tablets $1.0,2.5 \mathrm{mg}$ & 5.0 & $2.0-3.0$ & $60-180$ & $5.0-6.3$ & $63-74$ & 8.2 & High & $28-31$ & $\begin{array}{l}2.4 \\
\mathrm{~L} / \mathrm{kg}\end{array}$ & $\begin{array}{l}70 \% \text { renal, } \\
\text { CYP450 }\end{array}$ & $\begin{array}{l}\text { Urine } \\
(50 \%)\end{array}$ & $\begin{array}{l}\text { - Well tolerated, occasional } \\
\text { triptan sensations. }\end{array}$ \\
\hline $\begin{array}{l}\text { Frovatriptan } \\
\text { Frova }^{8}\end{array}$ & & Tablets $2.5 \mathrm{mg}$ & $\begin{array}{l}2.5 \text { (usual) } \\
5 \text { (maximum) }\end{array}$ & $2.0-4.0$ & $60-120$ & 25 & $24-30$ & 8.5 & Low & $20-30$ & $\begin{array}{l}3.0- \\
4.2 \\
\mathrm{~L} / \mathrm{kg}\end{array}$ & $\begin{array}{l}\text { Hepatic } \\
\text { MAO-A } \\
\text { CYP1A2 }\end{array}$ & $\begin{array}{l}\text { Urine } \\
(40 \%)\end{array}$ & $\begin{array}{l}\text { - Well tolerated, occasional } \\
\text { triptan sensations. }\end{array}$ \\
\hline
\end{tabular}

Avoid the use of almotriptan, rizatriptan, sumatriptan, and zolmitriptan with monoamine oxidase (MAO-A) inhibitors and within 2 weeks after discontinuation of MAO-O inhibitors

$\mathrm{T}_{\max }=$ time to peak plasma concentration; $\mathrm{T}_{1 / 2}=$ elimination half-life; $\mathrm{NNT}=$ number needed to treat; $\mathrm{V}_{\mathrm{D}}=$ volume of distribution; $\mathrm{SC}=$ subcutaneous; $\mathrm{EU}=$ European Union; $\mathrm{CYP}=$ cytochrome P450

*NNTs may be lower when attacks are treated early at mild intensity [4, 59, 147-149] 
Table 2 Comparison of the main efficacy and tolerability measures for the oral triptans versus sumatriptan $100 \mathrm{mg}$

\begin{tabular}{|c|c|c|c|c|c|}
\hline Triptan & Dose (mg) & Initial 2-h relief & Sustained pain-free response & Consistency & Tolerability \\
\hline \multirow[t]{2}{*}{ Sumatriptan } & 50 & $=$ & $=$ & $=/-$ & $=$ \\
\hline & 25 & - & $=/-$ & - & + \\
\hline \multirow[t]{2}{*}{ Zolmitriptan } & 2.5 & $=$ & $=$ & $=$ & + \\
\hline & 5 & $=$ & $=$ & $=$ & + \\
\hline Naratriptan & 2.5 & - & - & - & ++ \\
\hline \multirow[t]{2}{*}{ Rizatriptan } & 5 & $=$ & $=$ & $=$ & + \\
\hline & 10 & + & + & ++ & + \\
\hline \multirow[t]{3}{*}{ Eleptriptan } & 20 & - & - & - & + \\
\hline & 40 & $=/+$ & $=/+$ & + & + \\
\hline & 80 & $+(+)$ & + & + & - \\
\hline
\end{tabular}

Results are based on a meta-analysis and direct comparator trials. Sustained pain-free response is defined as patients who require only a single dose of triptan to abort an attack by $2 \mathrm{~h}$ and for at least $24 \mathrm{~h}$. Consistency is defined as the proportion of patients with a response (or pain free) in at least 2 or 3 of 3 actively treated attacks (adapted from [83]) $(=)=$ no difference when compared with sumatriptan; $(+)=$ better when compared with sumatriptan; $(-)=$ inferior when compared with sumatriptan

unlikely to be of additional benefits and other options need to be explored [85].

Triptans are generally safe in patients without concomitant vascular disease and are well tolerated [86]. They are contraindicated for patients with cardio- or cerebrovascular disease, uncontrolled hypertension, ischemic bowel, hemiplegic migraine, migraine with brainstem aura, pregnant or at risk for pregnancy, or who have used another triptan or ergotamine/ dihydroergotamine in the previous $24 \mathrm{~h}$ [87]. Triptan-induced sensations such as chest pressure and tingling in the limbs are relatively common (7\%), but this has not been associated with an increased risk of cardiovascular ischemia [86]. Triptans do not act on the $5-\mathrm{HT}_{2 \mathrm{~A}}$ receptors, and therefore do not appear to increase the risk of serotonin syndrome when used in monotherapy or when combined with selective serotonin reuptake inhibitors, and serotonin noradrenaline reuptake inhibitors [88]. In 2012, the American Headache Society published a position paper on this subject stating that the available evidence do not support the limitation of the use of triptans alone or together with selective serotonin reuptake inhibitors or serotonin noradrenaline reuptake inhibitors, owing to concerns over the serotonin syndrome. However, caution is certainly warranted and clinicians should be vigilant to signs and symptoms of toxicity [89].

Triptans should not be concomitantly used with ergotamine (within $24 \mathrm{~h}$ ) or monoamine oxidase inhibitors (within 2 weeks) to avoid additive effects, excessive constriction of blood vessels and increased triptans plasma levels. Sumatriptan, almotriptan, eletriptan, and naratriptan contain a sulfonyl group or a sulfonamide moiety, although patients with an allergy to sulfur usually tolerate these triptans well, if previous allergic reactions to sulfonamides have been severe, a sulfur-free triptan can be chosen (e.g., rizatriptan, frovatriptan, or zolmitriptan). Frequent intake of triptan is known to lead, in susceptible individuals, to a syndrome called $\mathrm{MOH}$. Hence it is recommended to limit the use of triptans to $<10$ days per month in order to decrease the risk of development of $\mathrm{MOH}$.

Despite the fact that the use of triptans is safely accepted for several types of migraine, their use in hemiplegic migraine is controversial and has not yet been proven to be safe. Hemiplegic migraine is a rare type of migraine accompanied by temporary paralysis of one side of the body. Triptans and ergotamines are contraindicated owing to their vasoconstrictive properties (risk of vessel spasm) and concerns about stroke. A study involving 76 patients with hemiplegic migraine treated with triptans concluded that they were safe and effective, but this study was too small to exclude potentially serious side effects [90]. Other studies have indicated that triptans may be safe in hemiplegic migraine [91], or are often used in hemiplegic migraine [92], or have listed them as treatment options if NSAIDs and other analgesics have failed [93].

\section{Nonspecific Pharmacological Treatments for Acute Migraines}

\section{NSAIDs}

The NSAIDs is a class of drugs widely used for the treatment of pain, fever, and inflammation. Generally, NSAIDs show their anti-inflammatory effects at higher doses than their analgesic and antipyretic properties. NSAIDs are grouped in several chemical classes and this chemical diversity leads to a range of pharmacokinetic characteristics (see Tables 3 and 4). Despite this diversity in kinetics, NSAIDs also show several properties in common. With the exception of nabumetone, 
Table 3 Nonsteroidal anti-inflammatory drug classification

\begin{tabular}{|c|c|c|c|}
\hline \multirow[t]{3}{*}{ Carboxylic acids } & $\begin{array}{l}\text { Arylpropionic acids } \\
\text { Flurbiprofen, ketoprofen, oxaproxin, } \\
\text { ibuprofen, naproxen, fenoprofen }\end{array}$ & Enolic acids & $\begin{array}{l}\text { - Pyrazolones } \\
\text { - Phenylbutazone } \\
\text { - Oxicams } \\
\text { - Piroxicam } \\
\text { - Meloxicam }\end{array}$ \\
\hline & $\begin{array}{l}\text { Salicylic acids } \\
\text { Aspirin, difunisal, trisalicylate salsalate, } \\
\quad \text { sodium salicylate, olsalazine, sulfasalazine }\end{array}$ & Nonacidic compounds & Nabumetone \\
\hline & $\begin{array}{l}\text { Anthranilic acids } \\
\text { Mefenamic acid, meclofenamic acid } \\
\text { Acetic acids } \\
\text { - Indole and indene acids } \\
\text { - Etodolac, indomethacin, sulindac, } \\
\text { tolmetin, ketorolac } \\
\text { - Phenylacetic } \\
\text { - Diclofenac }\end{array}$ & COX-2 selective inhibitors (Coxibs) & $\begin{array}{l}\text { Celecoxib } \\
\text { Rofecoxib } \\
\text { Meloxicam } \\
\text { Nimesulide } \\
\text { Paracoxib } \\
\text { Etodolac } \\
\text { Lumiracoxib } \\
\text { Valdecoxib } \\
\text { Deracoxib } \\
\text { Etoricoxib }\end{array}$ \\
\hline
\end{tabular}

$\mathrm{COX}=$ cyclooxygenase

all of the NSAIDs are weak organic acids, and this results in their accumulation at sites with low $\mathrm{pH}$, such as sites of inflammation. The majority of NSAIDs is well absorbed and their bioavailability is not influenced by food.

The main mechanism of action of NSAIDs is the inhibition of the synthesis of prostanoids (including prostaglandins and thromboxanes) from arachidonic acid. NSAIDs modify the activity of both cyclooxygenase- 1 (COX-1) and cyclooxygenase-2 (COX-2). COX-1 and COX-2 are the enzymes responsible for the catalysis of prostanoids, which are responsible for development of pain and inflammation (see Fig. 2). The inhibition of COX-2 exerts the anti-inflammatory, analgesic, and antipyretic effect, whereas the inhibition of COX-1 leads to gastrointestinal bleeding and ulceration [94]. The selectivity for COX-1 versus COX-2 is variable and incomplete for the older generation of NSAIDs (i.e., ibuprofen and naproxen); hence, more selective $\mathrm{COX}-2$ inhibitors have been synthesized (i.e., celecoxib and meloxicam). While the efficacy of new-generation NSAIDs, with COX-2 selectivity, is the same as that of older NSAIDs, the gastrointestinal safety is improved. However, the selective inhibition of COX-2 may lead to more cardiovascular adverse effects.

NSAIDs are widely used for acute migraine treatment. Their action is mainly to inhibit neurogenic inflammation and the reversal of central sensitization associated with migraine [95]. Several double-blind, randomized controlled studies have shown the efficacy for ibuprofen [96], naproxen sodium [97], ASA [21], and diclofenac potassium [98] for the treatment of migraine.

Ibuprofen is a very commonly used NSAID. It is a nonselective COX inhibitor very rapidly absorbed from the gastrointestinal tract and thus has a rapid onset of action. The NNT is 3.2 for headache relief at $2 \mathrm{~h}$ (pain reduced to mild or no pain), and 7.2 for pain freedom at $2 \mathrm{~h}$ [99]. The solubilized liquid-containing capsules have a faster onset of action, and better response rate for headache relief at $1 \mathrm{~h}$ than the tablet formulation [33]. Ibuprofen has a short half-life $(2 \mathrm{~h})$ and thus repeated dosing may be required. Additionally, it has been reported that higher doses do not provide better efficacy than the commonly used 400-mg dose [96]. The proportion of patients attaining headache relief at $2 \mathrm{~h}$ with ibuprofen $400 \mathrm{mg}$ [99] is comparable with that reached with ASA 900 to $1000 \mathrm{mg}$ [21]. However, less gastric irritation is associated with ibuprofen.

Diclofenac potassium is an NSAID with a fast onset of action, and a short half-life of $2 \mathrm{~h}$. Maximal plasma concentrations are achieved in under an hour with the tablet formulation and in $<15 \mathrm{~min}$ with the powdered formulation for oral solution $[32,100]$. For the powder formulation the NNT for the 2-h pain free end point is similar to ibuprofen. The common dose of diclofenac potassium is $50 \mathrm{mg}$, with a maximum daily dose of $150 \mathrm{mg}$. For single doses of diclofenac potassium $50 \mathrm{mg}$ versus placebo, the NNTs for pain freedom at $2 \mathrm{~h}$ was 6.2 , headache relief at $2 \mathrm{~h}$ was 8.9 , and pain-free responses at $24 \mathrm{~h}$ was 9.5 [98].

Naproxen has been shown to be consistently effective for the treatment of moderate-to-severe migraine attacks [97], it has a long duration of action, with a half-life of $14 \mathrm{~h}$. However, compared with ibuprofen, it has a slower onset of action. At $2 \mathrm{~h}$, the NNT for pain-free response was 11 [17\% response with naproxen, $8 \%$ with placebo; risk ratio 2.0 , 95\% confidence interval (CI) 1.6-2.6; moderate quality] and for headache relief was 6.0 (45\% response 


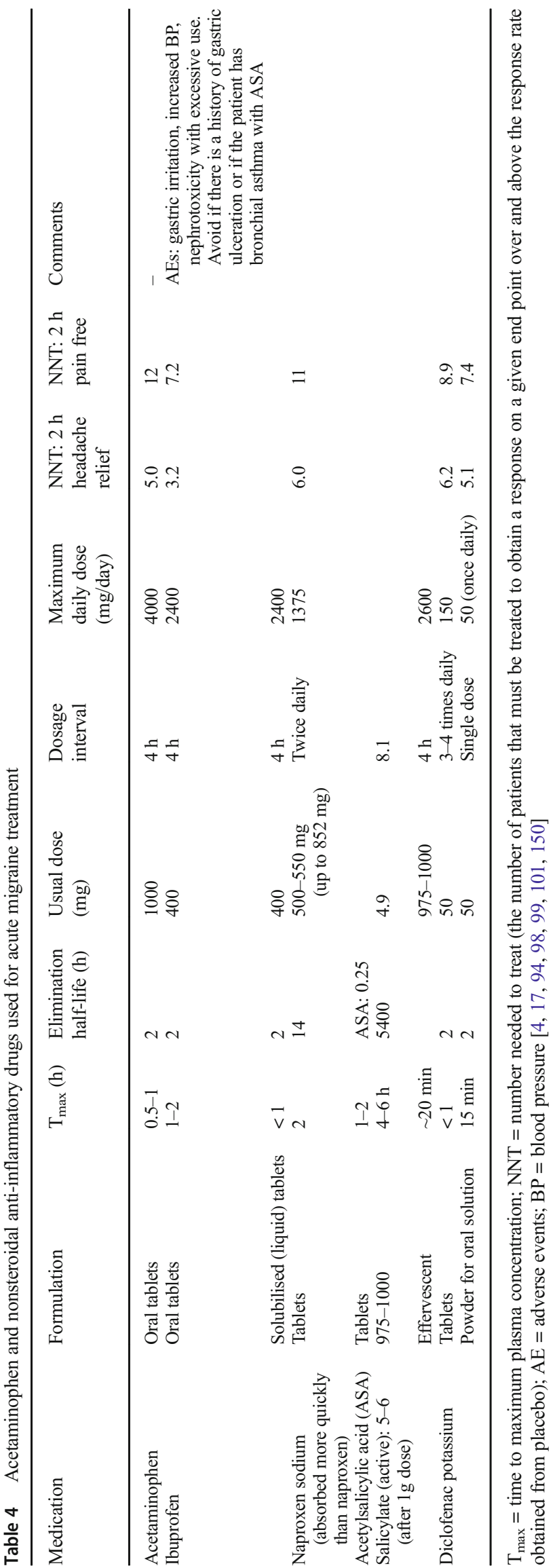

with naproxen, $29 \%$ with placebo; risk ratio $1.6,95 \% \mathrm{CI}$ 1.4-1.8; moderate quality) $[96,101]$. Compared with other NSAIDs, naproxen sodium has a relatively good cardiovascular safety profile and thus may be preferred in patients with concomitant cardiovascular disease [102]. The commonly used dose is $500 \mathrm{mg}$ or $550 \mathrm{mg}$. Naproxen sodium is preferred instead of naproxen owing to its faster onset of action, and the total daily dose should not exceed $1375 \mathrm{mg}$ [97]. However, anecdotally some clinicians argue that naproxen is preferred over naproxen sodium in patients with sodium restriction.

ASA (aspirin) is usually administered at 975 to 1000 $\mathrm{mg}$, with a maximum daily dose of $4000 \mathrm{mg}$. ASA has a relatively long half-life of $6 \mathrm{~h}$ mainly owing to the formation of active salicylate metabolites prior to its elimination. Effervescent ASA has a faster onset of action than the regular tablets, and has shown similar efficacy to that of sumatriptan $50 \mathrm{mg}$ [103] but higher than naproxen sodium $500 \mathrm{mg}$ [97]. The addition of metoclopramide $10 \mathrm{mg}$ improves the relief of nausea and vomiting associated with migraine [21].

Other NSAIDs may also be effective, but owing to a lack of evidence, they are not routinely recommended. Ketorolac has a rapid rate of absorption (maximum plasma levels occur in < $1 \mathrm{~h}$ ) with a relatively long half-life of $5 \mathrm{~h}$. The usual dose is $10 \mathrm{mg}$ and the maximum daily dose is $40 \mathrm{mg}$. It is recommended that patients do not take ketorolac for more than 5 to 7 days consecutively owing to concerns of nephrotoxicity and gastrointestinal adverse effects.

Categorically, NSAIDs are contraindicated in patients with peptic ulcer disease, inflammatory bowel disease, gastric bypass surgery, ASA allergy, renal dysfunction, and those on concomitant anticoagulants. In order to decrease the risk for the development of $\mathrm{MOH}$, the use of NSAIDs should be limited to 14 days a month or fewer.

\section{Acetaminophen}

Acetaminophen, commonly known as paracetamol, was developed in the nineteenth century. It became available by prescription in the UK in 1956, and subsequently over the counter in 1963. The active components of paracetamol are the 2 antipyretic active metabolites - acetanilide and phenacetin (see Table 4). The mechanism of action of paracetamol is still not completely understood, but its effects are probably achieved through the central inhibition of prostaglandin synthesis [104]. Differently from the NSAIDs, paracetamol does not directly inhibit COX functions outside the central nervous system, and its central action is not through direct blockage of an active site but rather through reduction of COX activity. Paracetamol is a very commonly used medication, and has evidence of efficacy in migraine as well [105]. It is usually used for migraine attacks of mild or moderate severity. For the treatment 


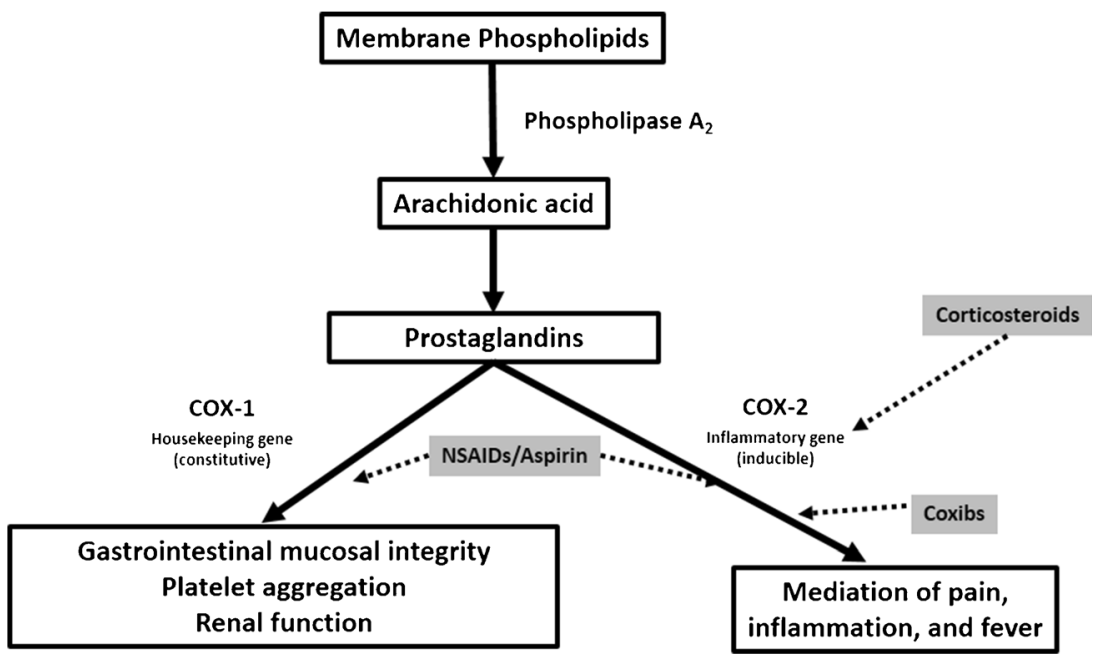

Fig. 2 Comparison of the mechanisms of action of the nonsteroidal antiinflammatory drugs (NSAIDs) and the Coxibs. The immediate precursor of prostaglandins, arachidonic acid, is derived from membrane phospholipids and is catalysed by the 2 cyclooxygenase isoenzymes - cyclooxygenase (COX)-1 and COX-2. The gene for COX-1, the housekeeping enzyme, is expressed constitutively and maintains the homeostasis of organs, including gastric mucosal integrity. In contrast, the gene for COX-2, the inflammatory enzyme, is inducible. Although both pathways can be variably inhibited by different NSAIDs, only the gene for COX-2 contains a corticosteroid-responsive repressor element in its promoter region. The broken arrows indicate the inhibitory effects of pharmacologic agents [150] of episodic tension-type headache or migraine attacks, Diener et al. [106] reported that, at $2 \mathrm{~h}$, administration of paracetamol $1000 \mathrm{mg}$ resulted in greater pain reduction, from moderate or severe to no pain (19\% and $10 \%$, respectively) versus placebo. Similarly, pain intensity went from moderate or severe to no worse than mild pain (56\% and $36 \%$, respectively). In addition, paracetamol $1000 \mathrm{mg}$ alone is an effective treatment for acute migraine headaches, and the addition of $10 \mathrm{mg}$ metoclopramide gives short-term efficacy equivalent to oral sumatriptan $100 \mathrm{mg}$ [107]. Paracetamol $1000 \mathrm{mg}$ was also found to be as effective as $1000 \mathrm{mg}$ of ASA [108]. However, compared with NSAIDs, acetaminophen has the advantage of causing fewer gastric side effects and it does not affect platelet function as prostaglandin synthesis in platelets is unaffected. The recommended dose of acetaminophen for migraine is $1000 \mathrm{mg}$ per dose. Owing to its short half-life of 2 to $3 \mathrm{~h}$, patients may need repeated dosing, but the total daily dose should not exceed $4000 \mathrm{mg}$ to avoid hepatotoxic side effects [109].

Acetaminophen may also be used in combination with other drugs. The combination of aspirin/paracetamol/caffeine has been demonstrated to have greater efficacy than any one of its components in comparable doses when administered alone [106]. Combinations that include opioids (e.g., paracetamol/codeine) should not be routinely used in migraine treatment owing to the poor evidence for efficacy beyond that provided by NSAIDs, and to the risk of developing $\mathrm{MOH}$. If the use of opioids is necessary a combination of analgesic with tramadol may be the preferred option [110]. Furthermore, the use of barbiturate mixtures (butalbital/caffeine/paracetamol or aspirin) should be avoided mainly because of risk of addiction [15]. In order to avoid $\mathrm{MOH}$, the use of acetaminophen alone should be limited to 14 days a month or fewer, and limited to 10 days a month or fewer when used in combination with other drugs.

\section{Dopamine Antagonists (The Antiemetics)}

Medications under this category are useful in the acute treatment of migraine and also as an adjunct treatment for the nausea experienced during migraine attacks [111]. The proposed mechanism of action of these agents may result from their dopamine antagonist properties, and the hypersensitivity to dopamine reported during a migraine attack [112]. Metoclopramide is commonly administered in the emergency department (ED) setting for the treatment of nausea and vomiting. It decreases gastric stasis, enhances absorption of concomitantly administered medications, and it is effective in migraine treatment during pregnancy [113]. As described above, the usual dose of metoclopramide is $10 \mathrm{mg}$, which may be safely administered up to 4 times a day. A metaanalysis of 13 randomized controlled trials concluded that IV metoclopramide should be considered first-line therapy for migraines in the ED, and suggests that metoclopramide has a primary effect on migraine, beyond its antiemetic property [113].

Both chlorpromazine and prochlorperazine are considered dopamine receptor antagonists (at D1, D2, D3, and D4 receptors), even if their antiemetic effects are due to the antagonism 
at the histaminergic receptor, H1. For patients who are refractory to the usual treatments, these medications could be tried. Compared with placebo, IV chlorpromazine $0.1 \mathrm{mg} / \mathrm{kg}$ has been shown to be effective in patients with migraine with or without aura [114]. In addition, IV chlorpromazine $25 \mathrm{mg}$ was found to be as effective as $60 \mathrm{mg}$ of intramuscular ketorolac. Patients that do not respond to chlorpromazine may respond to ketorolac and vice versa [115].

Prochlorperazine can be administered either orally $(10 \mathrm{mg}$, no more than 4 times a day) or via suppository (dosage range 10-25 $\mathrm{mg}$, maximum daily dose $50 \mathrm{mg}$ ). However, there is a higher risk of extrapyramidal side effects than with metoclopramide. Prochlorperazine has demonstrated effectiveness for acute migraine treatment in the ED setting with a response rate of $88 \%$ versus $45 \%$ in the placebo group [116].

All the above medications can safely be administered in combination with other commonly used drugs for the treatment of migraine attacks. However, several adverse effects may potentially occur in association with dopamine blockade, including drowsiness and weight gain (via blockade of histamine receptors), postural hypotension (via $\alpha 1$-adrenergic receptors), sedation, xerostomia, blurred vision, QT interval prolongation and cardiac arrhythmias, and urinary retention (via muscarinic cholinergic receptors). In addition, dopamine blockade can also cause extrapyramidal symptoms such as akathisia, tremors, dystonia, drug-induced pseudo-parkinsonism, and tardive dyskinesia. Increase in prolactin release producing sexual dysfunction, galactorrhoea, and infertility can also occur. However, these events are uncommon with the intermittent oral dosing used to treat migraine attacks.

\section{Corticosteroids}

The role of corticosteroids in acute migraine treatment has not been firmly established. Findings from animal experiments indicate that migraine pain may be partly caused by a sterile neurogenic inflammatory process in the dura mater [48].

The evidence for the role of corticosteroids in the prevention of migraine recurrence has been conflicting. Several trials attempted to address this issue, and found, for example, that dexamethasone failed to reduce headache relapse after ED discharge [117-119]. On the contrary, there is some support for its usage in the prevention of headache recurrence, especially if the migraine attack has lasted longer than $72 \mathrm{~h}[120$, 121].

\section{Opioids}

The use of opioids in migraine acute treatment is very controversial. Opioids modulate nociception in the trigeminovascular complex, and have neither vasopressor nor anti-inflammatory effects [112]. There is evidence that frequent use of opioids can induce central sensitization, and increase the risk of $\mathrm{MOH}[122,123]$. Even the intermittent use of opioids may interfere with the reversal of central sensitization in migraineurs [122]. In addition, there is also concern that opioids may make patients more refractory to other acute medications, including the triptans [123]. Evidence suggest that a recent use of opioids is associated with a lower response rate to rizatriptan [124]. The use of opioids should only be considered when other options have been tried or are deemed unsuitable, and the potential for abuse has been addressed [15].

\section{Migraine With Aura}

Evidence suggest that both subcutaneous sumatriptan and oral eletriptan are not as effective when taken during the aura phase of migraine. Thus, it is advisable that patients are administered a triptan at the onset of the headache pain phase. However, many patients experience pain onset during the aura phase. More studies are required to elucidate the safety of this practice, although anecdotally this is considered safe. There is some evidence that shows how sumatriptan taken during the aura phase yields good results [125].

\section{Refractory Migraine}

If patients do not respond to NSAIDs or triptans, it is important to reconsider if a correct diagnosis has been made and if a secondary headache may be present. Other factors for intractability such as lifestyle and medication-overuse headache should be considered and addressed. After these have been considered, there are several treatment options available for this group of patients, and these strategies are described elsewhere $[4,126]$. In addition, it is important to realize that a proportion of patients will not respond well to any of the acute migraine medications, and that pharmacological migraine prevention strategies may need to be instituted.

\section{Special Situations}

\section{Strategies for Patients With Contraindications to Vasoconstricting Drugs}

Acute treatment options for patients with contraindications to triptans include NSAIDs, dopamine antagonists, corticosteroids, and combination analgesics with codeine or tramadol. Nonopioid combination analgesics may also be helpful. Combination analgesics containing acetaminophen, aspirin, and caffeine have been found superior to the combination of acetaminophen and ASA without caffeine to ASA alone and to acetaminophen alone [106]. A combination of 
acetaminophen $400 \mathrm{mg}$ per day, ASA $500 \mathrm{mg}$ per day, and caffeine $100 \mathrm{mg}$ given as a single dose was found to be effective even in patients with severe headache attacks versus placebo [127]. Combination analgesics containing isometheptene are contraindicated in patients with vascular disease because of its vasoconstrictor properties. Patients with contraindications to triptans and who do not respond to NSAIDs might be the one group of patients where the use of opioid/analgesic combination tablets becomes necessary [128]. However, it is important to limit the use of combination analgesics to $<10$ days per month to avoid the development of $\mathrm{MOH}$.

\section{Strategies For Menstrual Migraine}

Menstrually related migraine is defined as attacks of migraine without aura that occur 2 days prior to the onset of menstruation to 3 days after the onset in at least 2 out of 3 menstrual cycles, and additionally at other times of the cycle. Attacks during this period are usually more severe, disabling, and longer-lasting. Also, these attacks are more likely to relapse than non-menstrually related migraine episodes in women with frequent menstrual migraine, and thus may be more difficult to manage [129]. Many triptans have shown good efficacy in treating these attacks [130-132]. In particular, a triptan with a longer half-life, especially frovatriptan, may be useful for the acute treatment of menstrual migraine. Post-hoc analyses from randomized trials of menstrual migraine demonstrate similar pain relief and pain-free rates for frovatriptan compared with other triptans [ $2 \mathrm{~h}$ pain-free: relative risk (RR) $1.27,95 \%$ CI $0.91-1.76$ ] but significantly lower relapse rates (24 h sustained pain-free: RR $0.34,95 \%$ CI $0.18-0.62$ ) [133]. If this initial treatment is not beneficial, the use of the triptan-naproxen sodium combination may be tried as this has been found to be efficacious in menstrual migraine [134]. In addition, the concomitant addition of dexamethasone $4 \mathrm{mg}$ to rizatriptan $10 \mathrm{mg}$ improves efficacy for menstrual migraine attacks beyond that of rizatriptan alone [135]. However, a proportion of patients may not respond to these strategies, and other short-term (mini-prophylaxis) or long-term preventive strategies may be warranted.

\section{Strategies During Pregnancy}

The pharmacological management of migraine during pregnancy and in the postpartum period is challenging owing to the potential risks to the fetus and the neonate. Acetaminophen is the analgesic of choice and could be an option for treating mild-to-moderate migraine attacks [4]. In addition, the combination of acetaminophen with codeine is also considered relatively safe. However, towards the end of pregnancy this should be avoided owing to the potential risk of the neonate developing withdrawal symptoms, a low-risk association with acute cesarean delivery, and postpartum hemorrhage [136]. ASA should be avoided in pregnancy. Other NSAIDs (e.g., ibuprofen) are preferable because of the less prolonged effects on platelet function [137]. The use of NSAIDs should be avoided in the first trimester owing to the risk of miscarriage and teratogenicity [138]. During the second trimester and the initial part of the third trimester, infrequent doses of NSAIDs could be considered when acetaminophen or nonpharmacological treatment options are not beneficial. Categorically, all NSAIDs should be avoided in the third trimester after the thirty-second week of gestation owing to the risk of premature closure of the ductus arteriosus [139].

The ergots are to be avoided during pregnancy owing to its effects on the uterus. On the contrary, triptans are much safer during pregnancy. A large observational study found no association between sumatriptan used in the first trimester (528 pregnancies) and teratogenicity or adverse pregnancy outcomes [140]. A Norwegian study reported that sumatriptan administered in the second and third trimester could result in uterine atony that may lead to hemorrhage and blood loss > $500 \mathrm{ml}$ during labor and delivery [141]. However, a subsequent Swedish study did not replicate this finding [142]. Despite the controversy, sumatriptan may still be considered during pregnancy, especially for migraines that are functionally disabling, or are accompanied by severe nausea and vomiting that results in maternal dehydration. Occipital nerve blocks containing lidocaine is safe during pregnancy, and can be a useful strategy. Prochlorperazine and other phenothiazines are not considered to be harmful to the fetus, but caution should be exercised near term as extrapyramidal effects in the newborn may be experienced.

\section{Strategies During Lactation}

Acetaminophen is considered safe to be administered during breastfeeding. Among the NSAIDs, ibuprofen is preferred owing to its short half-life. The infrequent administration of diclofenac or ketorolac is considered safe. However, ASA in analgesic doses should be avoided [143]. As the level of infant exposure from maternal use of sumatriptan appears to be minimal this drug is considered safe during lactation [144]. The antiemetics metoclopramide, domperidone, prochlorperazine, and dimenhydrinate are all considered safe while breastfeeding [4]. In the event that an opioid is considered, morphine is preferred. However, the breast milk should be discarded if the mother experiences significant sedation, and caution is needed when breastfeeding premature neonates. Because of variable maternal metabolism, codeine should be avoided, as the infant exposure to morphine, a metabolite of codeine, may be much higher than expected if the mother is a fast metabolizer of codeine (5-40\% of individuals, depending on ethnic background) [145]. 


\section{Conclusion}

Many of the current medications used for the acute treatment of migraine have shown efficacy in clinical trials. The choice of the most appropriate medication suitable for a patient is highly individualized and requires careful consideration based on the patient's clinical features, concomitant comorbidities, and preferences. This process is aided by a clear understanding of the pharmacodynamic and pharmacokinetic properties of the different drug options.

The management of migraine is multifaceted, for which the pharmacological treatment of acute migraine attacks should be complemented by other modalities such as lifestyle modification, trigger avoidance, behavioral, and pharmacological prevention. Even with the appropriate use of current acute treatments, there are still unmet therapeutic needs as not all patients may benefit from these available treatments. However, patients and physicians have much to look forward to, as recent advances in the understanding of migraine pathophysiology will, undoubtedly herald the development of new and more effective acute treatments.

Required Author Forms Disclosure forms provided by the authors are available with the online version of this article.

\section{References}

1. GBD 2015 Disease and Injury Incidence and Prevalence Collaborators. Global, regional, and national incidence, prevalence, and years lived with disability for 310 diseases and injuries, 1990-2015: a systematic analysis for the Global Burden of Disease Study 2015. Lancet. 2016;388(10053):1545-1602.

2. Lipton RB, Stewart WF, Diamond S, Diamond ML, Reed M. Prevalence and burden of migraine in the United States: data from the American Migraine Study II. Headache. 2001;41(7):646-657.

3. Cooke LJ, Becker WJ. Migraine prevalence, treatment and impact: the canadian women and migraine study. Can J Neurol Sci. 2010;37(5):580-587.

4. Worthington I, Pringsheim T, Gawel MJ, et al. Canadian Headache Society Guideline: acute drug therapy for migraine headache. Can J Neurol Sci. 2013;40(5 Suppl. 3):S1-S80.

5. Headache Classification Committee of the International Headache Society (HIS). The International Classification of Headache Disorders, 3rd edition (beta version). Cephalalgia. 2013;33(9): 629-808.

6. Giffin NJ, Ruggiero L, Lipton RB, et al. Premonitory symptoms in migraine: an electronic diary study. Neurology. 2003;60(6):935940.

7. Kelman L. The premonitory symptoms (prodrome): a tertiary care study of 893 migraineurs. Headache. 2004;44(9):865-872.

8. Giffin NJ, Lipton RB, Silberstein SD, Olesen J, Goadsby PJ. The migraine postdrome: an electronic diary study. Neurology. 2016;87(3):309-313.

9. Rasmussen BK, Olesen J. Migraine with aura and migraine without aura: an epidemiological study. Cephalalgia. 1992;12(4):221-228.
10. Goadsby PJ, Holland PR, Martins-Oliveira M, Hoffmann J, Schankin C, Akerman S. Pathophysiology of migraine: a disorder of sensory processing. Physiol Rev. 2017;97(2):553-622.

11. Akerman S, Holland PR, Goadsby PJ. Diencephalic and brainstem mechanisms in migraine. Nat Rev Neurosci. 2011;12(10):570-584.

12. Charles A. Advances in the basic and clinical science of migraine. Ann Neurol. 2009;65(5):491-498.

13. Pietrobon D, Striessnig J. Neurobiology of migraine. Nat Rev Neurosci. 2003;4(5):386-398.

14. Noseda R, Borsook D, Burstein R. Neuropeptides and neurotransmitters that modulate thalamo-cortical pathways relevant to migraine headache. Headache. 2017;57(Suppl. 2):97-111.

15. Silberstein SD. Practice parameter: evidence-based guidelines for migraine headache (an evidence-based review): report of the Quality Standards Subcommittee of the American Academy of Neurology. Neurology. 2000;55(6):754-762.

16. Tfelt-Hansen P, Pascual J, Ramadan N, et al. Guidelines for controlled trials of drugs in migraine: third edition. A guide for investigators. Cephalalgia. 2012;32(1):6-38.

17. Marmura MJ, Silberstein SD, Schwedt TJ. The acute treatment of migraine in adults: the american headache society evidence assessment of migraine pharmacotherapies. Headache. 2015;55(1):3-20.

18. Lipton RB, Stewart WF, Stone AM, Lainez MJ, Sawyer JP, Disability in Strategies of Care Study group. Stratified care vs step care strategies for migraine: the Disability in Strategies of Care (DISC) Study: a randomized trial. JAMA. 2000;284(20):2599-2605.

19. Sculpher M, Millson D, Meddis D, Poole L. Cost-effectiveness analysis of stratified versus stepped care strategies for acute treatment of migraine: The Disability in Strategies for Care (DISC) Study. Pharmacoeconomics. 2002;20(2):91-100.

20. Ahrens SP, Farmer MV, Williams DL, et al. Efficacy and safety of rizatriptan wafer for the acute treatment of migraine. Rizatriptan Wafer Protocol 049 Study Group. Cephalalgia. 1999;19(5):525-530.

21. Kirthi V, Derry S, Moore RA. Aspirin with or without an antiemetic for acute migraine headaches in adults. Cochrane Database Syst Rev. 2013(4):CD008041.

22. Geraud G, Compagnon A, Rossi A; COZAM Study Group. Zolmitriptan versus a combination of acetylsalicylic acid and metoclopramide in the acute oral treatment of migraine: a double-blind, randomised, three-attack study. Eur Neurol. 2002;47(2): 88-98.

23. Schulman EA, Dermott KF. Sumatriptan plus metoclopramide in triptan-nonresponsive migraineurs. Headache. 2003;43(7): 729-733.

24. Tfelt-Hansen P, Henry P, Mulder LJ, Scheldewaert RG, Schoenen J, Chazot G. The effectiveness of combined oral lysine acetylsalicylate and metoclopramide compared with oral sumatriptan for migraine. Lancet. 1995;346(8980):923-926.

25. Evers S, Afra J, Frese A, et al. EFNS guideline on the drug treatment of migraine - revised report of an EFNS task force. Eur J Neurol. 2009;16(9):968-981.

26. MacGregor EA, Wilkinson M, Bancroft K. Domperidone plus paracetamol in the treatment of migraine. Cephalalgia. 1993;13(2):124-127.

27. Doggrell SA, Hancox JC. Cardiac safety concerns for domperidone, an antiemetic and prokinetic, and galactogogue medicine. Expert Opin Drug Saf. 2014;13(1):131-138.

28. Charlesworth BR, Dowson AJ, Purdy A, Becker WJ, BoesHansen S, Farkkila M. Speed of onset and efficacy of zolmitriptan nasal spray in the acute treatment of migraine: a randomised, double-blind, placebo-controlled, dose-ranging study versus zolmitriptan tablet. CNS Drugs. 2003;17(9):653-667. 
29. Jones EB, Gonzalez ER, Boggs JG, Grillo JA, Elswick RK, Jr. Safety and efficacy of rectal prochlorperazine for the treatment of migraine in the emergency department. Ann Emerg Med. 1994;24(2):237-241.

30. The Subcutaneous Sumatriptan International Study Group. Treatment of migraine attacks with sumatriptan. N Engl J Med. 1991;325(5):316-321.

31. Tepper SJ, Chen S, Reidenbach F, Rapoport AM. Intranasal zolmitriptan for the treatment of acute migraine. Headache. 2013;53(Suppl. 2):62-71.

32. Diener HC, Montagna P, Gacs G, et al. Efficacy and tolerability of diclofenac potassium sachets in migraine: a randomized, doubleblind, cross-over study in comparison with diclofenac potassium tablets and placebo. Cephalalgia. 2006;26(5):537-547.

33. Kellstein DE, Lipton RB, Geetha R, et al. Evaluation of a novel solubilized formulation of ibuprofen in the treatment of migraine headache: a randomized, double-blind, placebo-controlled, doseranging study. Cephalalgia. 2000;20(4):233-243.

34. Lange R, Schwarz JA, Hohn M. Acetylsalicylic acid effervescent $1000 \mathrm{mg}$ (Aspirin) in acute migraine attacks; a multicentre, randomized, double-blind, single-dose, placebo-controlled parallel group study. Cephalalgia. 2000;20(7):663-667.

35. Freitag F, Smith T, Mathew N, et al. Effect of early intervention with almotriptan vs placebo on migraine-associated functional disability: results from the AEGIS Trial. Headache. 2008;48(3): 341-354.

36. Brandes JL, Kudrow D, Cady R, Tiseo PJ, Sun W, Sikes CR. Eletriptan in the early treatment of acute migraine: influence of pain intensity and time of dosing. Cephalalgia. 2005;25(9): 735-742.

37. Lipton RB, Munjal S, Buse DC, et al. Allodynia is associated with initial and sustained response to acute migraine treatment: results from the American Migraine Prevalence and Prevention Study. Headache. 2017;57(7):1026-1040.

38. Goadsby PJ, Zanchin G, Geraud G, et al. Early vs. non-early intervention in acute migraine-'Act when Mild (AwM)'. A double-blind, placebo-controlled trial of almotriptan. Cephalalgia. 2008;28(4):383-391.

39. Ferrari MD, James MH, Bates D, et al. Oral sumatriptan: effect of a second dose, and incidence and treatment of headache recurrences. Cephalalgia. 1994;14(5):330-338.

40. Thorlund K, Mills EJ, Wu P, et al. Comparative efficacy of triptans for the abortive treatment of migraine: a multiple treatment comparison meta-analysis. Cephalalgia. 2014;34(4):258-267.

41. Geraud G, Keywood C, Senard JM. Migraine headache recurrence: relationship to clinical, pharmacological, and pharmacokinetic properties of triptans. Headache. 2003;43(4):376-388.

42. Brandes JL, Kudrow D, Stark SR, et al. Sumatriptan-naproxen for acute treatment of migraine: a randomized trial. JAMA. 2007;297(13):1443-1454.

43. Smith TR, Sunshine A, Stark SR, Littlefield DE, Spruill SE, Alexander WJ. Sumatriptan and naproxen sodium for the acute treatment of migraine. Headache. 2005;45(8):983-991.

44. Winner P, Ricalde O, Le Force B, Saper J, Margul B. A doubleblind study of subcutaneous dihydroergotamine vs subcutaneous sumatriptan in the treatment of acute migraine. Arch Neurol. 1996;53(2):180-184.

45. Thompson MR. The active constituents of ergot: a pharmacological and chemical study. J Am Pharm Assoc 1935;24(1):24-38.

46. Saper JR, Silberstein S. Pharmacology of dihydroergotamine and evidence for efficacy and safety in migraine. Headache. 2006;46(Suppl. 4):S171-S181.

47. Goadsby PJ, Edvinsson L. The trigeminovascular system and migraine: studies characterizing cerebrovascular and neuropeptide changes seen in humans and cats. Ann Neurol 1993;33(1):48-56.
48. Markowitz S, Saito K, Moskowitz MA. Neurogenically mediated plasma extravasation in dura mater: effect of ergot alkaloids. A possible mechanism of action in vascular headache. Cephalalgia. 1988;8(2):83-91.

49. Muller-Schweinitzer E. Venoconstrictor responses to dihydroergocristine and dihydroergotamine: evidence for the involvement of 5-HT1 like receptors. Cardiovasc Drugs Ther. 1990;4(6): 1455-1460.

50. Muller-Schweinitzer E, Rosenthaler J. Dihydroergotamine: pharmacokinetics, pharmacodynamics, and mechanism of venoconstrictor action in beagle dogs. J Cardiovasc Pharmacol. 1987;9(6):686-693.

51. Kelley NE, Tepper DE. Rescue therapy for acute migraine, part 1: triptans, dihydroergotamine, and magnesium. Headache. 2012;52(1):114-128.

52. Moskowitz MA. Basic mechanisms in vascular headache. Neurol Clin 1990;8(4):801-815.

53. Masterson CG, Durham PL. DHE repression of ATP-mediated sensitization of trigeminal ganglion neurons. Headache. 2010;50(9):1424-1439.

54. Nagy AJ, Gandhi S, Bhola R, Goadsby PJ. Intravenous dihydroergotamine for inpatient management of refractory primary headaches. Neurology. 2011;77(20):1827-1832.

55. Horton BT PG, Blumenthal LS. A new product in the treatment of migraine: a preliminary report. Proc Staff Meet Mayo Clin. 1945;20:241-248.

56. Callaham M, Raskin N. A controlled study of dihydroergotamine in the treatment of acute migraine headache. Headache. 1986;26(4):168-171.

57. Raskin NH. Repetitive intravenous dihydroergotamine as therapy for intractable migraine. Neurology. 1986;36(7):995-997.

58. Silberstein SD, Young WB. Safety and efficacy of ergotamine tartrate and dihydroergotamine in the treatment of migraine and status migrainosus. Working Panel of the Headache and Facial Pain Section of the American Academy of Neurology. Neurology. 1995;45(3 Pt 1):577-584.

59. Tepper SJ, Spears RC. Acute treatment of migraine. Neurol Clin 2009;27(2):417-427.

60. Shrewsbury SB, Cook RO, Taylor G, Edwards C, Ramadan NM. Safety and pharmacokinetics of dihydroergotamine mesylate administered via a Novel (Tempo) inhaler. Headache. 2008;48(3): 355-367.

61. Stoll A. Zur Kenntnis der Mutterkornalkaloid. Verb, schweiz. Naturf. Ges., Neuenburg, 1920;101:190-191.

62. Maier HW. L'ergotamine, inhibiteur du sympathique étudié en clinique, comme moyen d'exploration et comme agent thérapeutique. Rev Neurol. 1926;33:1104-8.

63. Tfelt-Hansen P, Saxena PR, Dahlof C, et al. Ergotamine in the acute treatment of migraine: a review and European consensus. Brain. 2000;123 (Pt 1):9-18.

64. Sanders SW, Haering N, Mosberg H, Jaeger H. Pharmacokinetics of ergotamine in healthy volunteers following oral and rectal dosing. Eur J Clin Pharmacol 1986;30(3):331-334.

65. Tfelt-Hansen PJE. Ergotamine. In: Olesen JT-HP, Welch KM, editor. The headaches. New York: Raven Press; 1993. p. 313-322.

66. A randomized, double-blind comparison of sumatriptan and Cafergot in the acute treatment of migraine. The Multinational Oral Sumatriptan and Cafergot Comparative Study Group. Eur Neurol. 1991;31(5):314-322.

67. Johnston BM, Saxena PR. The effect of ergotamine on tissue blood flow and the arteriovenous shunting of radioactive microspheres in the head. Br J Pharmacol. 1978;63(3):541-549.

68. De Vries P, Villalon CM, Heiligers JP, Saxena PR. Characterization of 5-HT receptors mediating constriction of porcine carotid arteriovenous anastomoses; involvement of 5-HT1B/ 1D and novel receptors. Br J Pharmacol. 1998;123(8):1561-1570. 
69. Cortijo J, Marti-Cabrera M, Bernabeu E, et al. Characterization of 5-HT receptors on human pulmonary artery and vein: functional and binding studies. Br J Pharmacol. 1997;122(7):1455-1463.

70. Muller-Schweinitzer E, Fanchamps A. Effects on arterial receptors of ergot derivatives used in migraine. Adv Neurol. 1982;33:343-356.

71. MaassenVanDenBrink A, Reekers M, Bax WA, Ferrari MD, Saxena PR. Coronary side-effect potential of current and prospective antimigraine drugs. Circulation. 1998;98(1):25-30.

72. Galer BS, Lipton RB, Solomon S, Newman LC, Spierings EL. Myocardial ischemia related to ergot alkaloids: a case report and literature review. Headache. 1991;31(7):446-450.

73. Saxena PR, Ferrari MD. 5-HT(1)-like receptor agonists and the pathophysiology of migraine. Trends Pharmacol Sci 1989;10(5): 200-204.

74. Hargreaves RJ, Shepheard SL. Pathophysiology of migrainenew insights. Can J Neurol Sci. 1999;26(Suppl. 3):S12-S19.

75. Ahn AH, Basbaum AI. Where do triptans act in the treatment of migraine? Pain. 2005;115(1-2):1-4.

76. Humphrey PP, Feniuk W, Perren MJ, Connor HE, Oxford AW. The pharmacology of the novel 5-HT1-like receptor agonist, GR43175. Cephalalgia. 1989;9(Suppl. 9):23-33.

77. Humphrey PP, Feniuk W, Perren MJ, Beresford IJ, Skingle M, Whalley ET. Serotonin and migraine. Ann N Y Acad Sci 1990;600:587-598.

78. Humphrey PP, Feniuk W, Perren MJ. Anti-migraine drugs in development: advances in serotonin receptor pharmacology. Headache. 1990;30(1 Suppl):12-16.

79. Humphrey PP, Feniuk W, Marriott AS, Tanner RJ, Jackson MR, Tucker ML. Preclinical studies on the anti-migraine drug, sumatriptan. Eur Neurol. 1991;31(5):282-290.

80. Humphrey PP, Feniuk W. Mode of action of the anti-migraine drug sumatriptan. Trends Pharmacol Sci 1991;12(12):444-446.

81. Lipton RB, Bigal ME, Goadsby PJ. Double-blind clinical trials of oral triptans vs other classes of acute migraine medication - a review. Cephalalgia. 2004;24(5):321-332.

82. Rapoport AM, Tepper SJ, Sheftell FD, Kung E, Bigal ME. Which triptan for which patient? Neurological sciences : official journal of the Italian Neurological Society and of the Italian Society of Clinical Neurophysiology. 2006;27(Suppl. 2):S123-S129.

83. Ferrari MD, Roon KI, Lipton RB, Goadsby PJ. Oral triptans (serotonin 5-HT(1B/1D) agonists) in acute migraine treatment: a meta-analysis of 53 trials. Lancet 2001;358(9294):1668-1675.

84. Farkkila M, Olesen J, Dahlof C, et al. Eletriptan for the treatment of migraine in patients with previous poor response or tolerance to oral sumatriptan. Cephalalgia. 2003;23(6):463-471.

85. Tepper SJ, Donnan GA, Dowson AJ, et al. A long-term study to maximise migraine relief with zolmitriptan. Curr Med Res Opin 1999;15(4):254-271.

86. Dodick D, Lipton RB, Martin V, et al. Consensus statement: cardiovascular safety profile of triptans (5-HT agonists) in the acute treatment of migraine. Headache. 2004;44(5):414-425.

87. Rapoport AM, Tepper SJ, Bigal ME, Sheftell FD. The triptan formulations: how to match patients and products. CNS Drugs. 2003;17(6):431-447.

88. Gillman PK. Triptans, serotonin agonists, and serotonin syndrome (serotonin toxicity): a review. Headache. 2010;50(2):264-272.

89. Evans RW, Tepper SJ, Shapiro RE, Sun-Edelstein C, Tietjen GE. The FDA alert on serotonin syndrome with use of triptans combined with selective serotonin reuptake inhibitors or selective serotonin-norepinephrine reuptake inhibitors: American Headache Society position paper. Headache. 2010;50(6):10891099.

90. Artto V, Nissila M, Wessman M, Palotie A, Farkkila M, Kallela M. Treatment of hemiplegic migraine with triptans. Eur J Neurol. 2007;14(9):1053-1056.
91. Klapper J, Mathew N, Nett R. Triptans in the treatment of basilar migraine and migraine with prolonged aura. Headache. 2001;41(10):981-984.

92. Russell MB, Ducros A. Sporadic and familial hemiplegic migraine: pathophysiological mechanisms, clinical characteristics, diagnosis, and management. Lancet Neurol 2011;10(5):457-470.

93. Pelzer N, Stam AH, Haan J, Ferrari MD, Terwindt GM. Familial and sporadic hemiplegic migraine: diagnosis and treatment. Curr Treat Options Neurol 2013;15(1):13-27.

94. Silberstein SD, Stirpe JC. COX inhibitors for the treatment of migraine. Expert Opin Pharmacother 2014;15(13):1863-1874.

95. Tepper DE. Non-steroidal anti-inflammatories for the acute treatment of migraine. Headache. 2013;53(1):225-226.

96. Suthisisang C, Poolsup N, Kittikulsuth W, Pudchakan P, Wiwatpanich P. Efficacy of low-dose ibuprofen in acute migraine treatment: systematic review and meta-analysis. Ann Pharmacother 2007;41(11):1782-1791.

97. Suthisisang CC, Poolsup N, Suksomboon N, Lertpipopmetha V, Tepwitukgid B. Meta-analysis of the efficacy and safety of naproxen sodium in the acute treatment of migraine. Headache. 2010;50(5):808-818.

98. Derry S, Rabbie R, Moore RA. Diclofenac with or without an antiemetic for acute migraine headaches in adults. Cochrane Database Syst Rev. 2013(4):CD008783.

99. Rabbie R, Derry S, Moore RA. Ibuprofen with or without an antiemetic for acute migraine headaches in adults. Cochrane Database Syst Rev. 2013(4):CD008039.

100. Lipton RB, Grosberg B, Singer RP, et al. Efficacy and tolerability of a new powdered formulation of diclofenac potassium for oral solution for the acute treatment of migraine: results from the International Migraine Pain Assessment Clinical Trial (IMPACT). Cephalalgia. 2010;30(11):1336-1345.

101. Law S, Derry S, Moore RA. Naproxen with or without an antiemetic for acute migraine headaches in adults. Cochrane Database Syst Rev. 2013(10):CD009455.

102. Trelle S, Reichenbach S, Wandel S, et al. Cardiovascular safety of non-steroidal anti-inflammatory drugs: network meta-analysis. BMJ 2011;342:c7086.

103. Lampl C, Voelker M, Diener HC. Efficacy and safety of 1,000 mg effervescent aspirin: individual patient data meta-analysis of three trials in migraine headache and migraine accompanying symptoms. J Neurol 2007;254(6):705-712.

104. Graham GG, Scott KF. Mechanisms of action of paracetamol and related analgesics. Inflammopharmacology. 2003;11(4):401-413.

105. Lipton RB, Baggish JS, Stewart WF, Codispoti JR, Fu M. Efficacy and safety of acetaminophen in the treatment of migraine: results of a randomized, double-blind, placebo-controlled, populationbased study. Arch Intern Med 2000;160(22):3486-3492.

106. Diener HC, Pfaffenrath V, Pageler L, Peil H, Aicher B. The fixed combination of acetylsalicylic acid, paracetamol and caffeine is more effective than single substances and dual combination for the treatment of headache: a multicentre, randomized, doubleblind, single-dose, placebo-controlled parallel group study. Cephalalgia. 2005;25(10):776-787.

107. Derry S, Moore RA, McQuay HJ. Paracetamol (acetaminophen) with or without an antiemetic for acute migraine headaches in adults. Cochrane Database Syst Rev. 2010(11):CD008040.

108. Tfelt-Hansen P, Olesen J. Paracetamol (acetaminophen) versus acetylsalicylic acid in migraine. Eur Neurol. 1980;19(3):163-165.

109. Watkins PB, Kaplowitz N, Slattery JT, et al. Aminotransferase elevations in healthy adults receiving 4 grams of acetaminophen daily: a randomized controlled trial. JAMA. 2006;296(1):87-93.

110. Silberstein SD, Freitag FG, Rozen TD, et al. Tramadol/ acetaminophen for the treatment of acute migraine pain: findings of a randomized, placebo-controlled trial. Headache. 2005;45(10):1317-1327. 
111. Marmura MJ. Use of dopamine antagonists in treatment of migraine. Curr Treat Options Neurol 2012;14(1):27-35.

112. Barbanti P, Fofi L, Aurilia C, Egeo G. Dopaminergic symptoms in migraine. Neurol Sci 2013;34(Suppl. 1):S67-S70.

113. Colman I, Brown MD, Innes GD, Grafstein E, Roberts TE, Rowe BH. Parenteral metoclopramide for acute migraine: meta-analysis of randomised controlled trials. BMJ 2004;329(7479):1369-1373.

114. Bigal ME, Bordini CA, Speciali JG. Intravenous chlorpromazine in the emergency department treatment of migraines: a randomized controlled trial. J Emerg Med 2002;23(2):141-148.

115. Shrestha M, Singh R, Moreden J, Hayes JE. Ketorolac vs chlorpromazine in the treatment of acute migraine without aura. A prospective, randomized, double-blind trial. Arch Intern Med 1996;156(15):1725-1728.

116. Jones J, Sklar D, Dougherty J, White W. Randomized doubleblind trial of intravenous prochlorperazine for the treatment of acute headache. JAMA 1989;261(8):1174-1176.

117. Donaldson D, Sundermann R, Jackson R, Bastani A. Intravenous dexamethasone vs placebo as adjunctive therapy to reduce the recurrence rate of acute migraine headaches: a multicenter, double-blinded, placebo-controlled randomized clinical trial. Am J Emerg Med 2008;26(2):124-130.

118. Rowe BH, Colman I, Edmonds ML, Blitz S, Walker A, Wiens S. Randomized controlled trial of intravenous dexamethasone to prevent relapse in acute migraine headache. Headache. 2008;48(3): 333-340.

119. Fiesseler FW, Shih R, Szucs P, et al. Steroids for migraine headaches: a randomized double-blind, two-armed, placebo-controlled trial. J Emerg Med 2011;40(4):463-468.

120. Friedman BW, Greenwald P, Bania TC, et al. Randomized trial of IV dexamethasone for acute migraine in the emergency department. Neurology. 2007;69(22):2038-2044.

121. Kelley NE, Tepper DE. Rescue therapy for acute migraine, part 3: opioids, NSAIDs, steroids, and post-discharge medications. Headache. 2012;52(3):467-482.

122. Bigal ME, Lipton RB. Excessive opioid use and the development of chronic migraine. Pain. 2009;142(3):179-182.

123. Bigal ME, Lipton RB. Excessive acute migraine medication use and migraine progression. Neurology. 2008;71(22):1821-1828.

124. Ho TW, Rodgers A, Bigal ME. Impact of recent prior opioid use on rizatriptan efficacy. A post hoc pooled analysis. Headache. 2009;49(3):100-403.

125. Aurora SK, Barrodale PM, McDonald SA, Jakubowski M, Burstein R. Revisiting the efficacy of sumatriptan therapy during the aura phase of migraine. Headache. 2009;49(7):1001-4.

126. Becker WJ. Acute Migraine Treatment. Continuum (Minneap Minn). 2015;21(4 Headache):953-972.

127. Diener HC, Peil H, Aicher B. The efficacy and tolerability of a fixed combination of acetylsalicylic acid, paracetamol, and caffeine in patients with severe headache: a post-hoc subgroup analysis from a multicentre, randomized, double-blind, single-dose, placebo-controlled parallel group study. Cephalalgia. 2011;31(14):1466-1476.

128. Levin M. Opioids in headache. Headache. 2014;54(1):12-21.

129. MacGregor EA, Victor TW, Hu X, et al. Characteristics of menstrual vs nonmenstrual migraine: a post hoc, within-woman analysis of the usual-care phase of a nonrandomized menstrual migraine clinical trial. Headache. 2010;50(4):528-538.

130. Mannix LK, Loder E, Nett R, et al. Rizatriptan for the acute treatment of ICHD-II proposed menstrual migraine: two prospective, randomized, placebo-controlled, double-blind studies. Cephalalgia. 2007;27(5):414-421.
131. Tuchman M, Hee A, Emeribe U, Silberstein S. Efficacy and tolerability of zolmitriptan oral tablet in the acute treatment of menstrual migraine. CNS Drugs. 2006;20(12):1019-1026.

132. Pringsheim T, Davenport WJ, Dodick D. Acute treatment and prevention of menstrually related migraine headache: evidencebased review. Neurology. 2008;70(17):1555-1563.

133. MacGregor EA. A review of frovatriptan for the treatment of menstrual migraine. Int J Womens Health. 2014;6:523-535.

134. Mannix LK, Martin VT, Cady RK, et al. Combination treatment for menstrual migraine and dysmenorrhea using sumatriptannaproxen: two randomized controlled trials. Obstet Gynecol 2009;114(1):106-113.

135. Bigal M, Sheftell F, Tepper S, Tepper D, Ho TW, Rapoport A. A randomized double-blind study comparing rizatriptan, dexamethasone, and the combination of both in the acute treatment of menstrually related migraine. Headache. 2008;48(9):1286-1293.

136. Nezvalova-Henriksen K, Spigset O, Nordeng H. Effects of codeine on pregnancy outcome: results from a large populationbased cohort study. Eur J Clin Pharmacol 2011;67(12):1253-1261.

137. MacGregor EA. Pharmacological management of migraine in pregnancy. In: Mitsikostas DD, Paemeleire K, editors. Pharmacological Management of Headaches. Switzerland: Springer International Publishing; 2016. p. 155-166.

138. Li DK, Liu L, Odouli R. Exposure to non-steroidal anti-inflammatory drugs during pregnancy and risk of miscarriage: population based cohort study. BMJ 2003;327(7411):368.

139. Koren G, Florescu A, Costei AM, Boskovic R, Moretti ME. Nonsteroidal antiinflammatory drugs during third trimester and the risk of premature closure of the ductus arteriosus: a metaanalysis. Ann Pharmacother 2006;40(5):824-829.

140. Ephross SA, Sinclair SM. Final results from the 16-year sumatriptan, naratriptan, and treximet pregnancy registry. Headache. 2014;54(7):1158-1172.

141. Nezvalova-Henriksen K, Spigset O, Nordeng H. Triptan exposure during pregnancy and the risk of major congenital malformations and adverse pregnancy outcomes: results from the Norwegian Mother and Child Cohort Study. Headache. 2010;50(4):563-575.

142. Kallen B, Nilsson E, Otterblad Olausson P. Delivery outcome after maternal use of drugs for migraine: a register study in Sweden. Drug Saf. 2011;34(8):691-703.

143. Daniel S, Koren G, Lunenfeld E, Bilenko N, Ratzon R, Levy A. Fetal exposure to nonsteroidal anti-inflammatory drugs and spontaneous abortions. CMAJ 2014;186(5):E177-E182.

144. Ward RM BB, Benitz WE, Burchfield DJ, et al. The transfer of drugs and other chemicals into human milk. Pediatrics. 2001;108 (3):776-789.

145. Hendrickson RG, McKeown NJ. Is maternal opioid use hazardous to breast-fed infants? Clin Toxicol (Phila). 2012;50(1):1-14.

146. Akerman S, Romero-Reyes M. Insights into the pharmacological targeting of the trigeminocervical complex in the context of treatments of migraine. Expert Rev Neurother. 2013;13(9):1041-1059.

147. Mathew NT, Loder EW. Evaluating the triptans. Am J Med 2005;118(Suppl. 1):28s-35s.

148. Bigal ME, Bordini CA, Antoniazzi AL, Speciali JG. The triptan formulations: a critical evaluation. Arq Neuropsiquiatr 2003;61(2a):313-320.

149. Jhee SS, Shiovitz T, Crawford AW, Cutler NR. Pharmacokinetics and pharmacodynamics of the triptan antimigraine agents: a comparative review. Clin Pharmacokinet 2001;40(3):189-205.

150. Wolfe MM, Lichtenstein DR, Singh G. Gastrointestinal toxicity of nonsteroidal antiinflammatory drugs. N Engl J Med. 1999;340(24):1888-1899. 